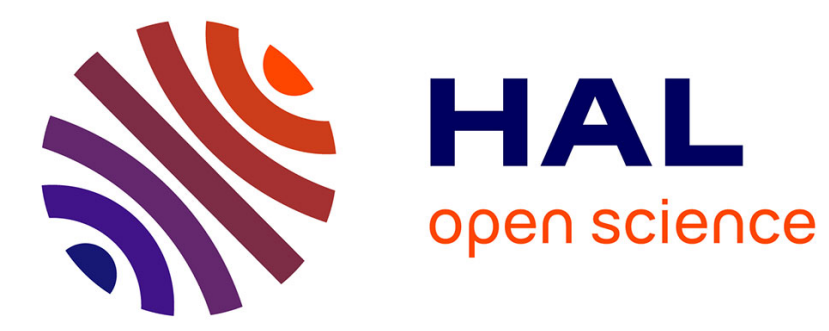

\title{
General Analytical Magnetic Model for Partitioned-Stator Flux-Reversal Machines With Four Types of Magnetization Patterns
}

\author{
Amir Abbas Vahaj, Akbar Rahideh, Thierry Lubin
}

\section{- To cite this version:}

Amir Abbas Vahaj, Akbar Rahideh, Thierry Lubin. General Analytical Magnetic Model for Partitioned-Stator Flux-Reversal Machines With Four Types of Magnetization Patterns. IEEE Transactions on Magnetics, 2019, 55 (11), pp.1-21. 10.1109/TMAG.2019.2929477 . hal-02376891

\section{HAL Id: hal-02376891 \\ https://hal.science/hal-02376891}

Submitted on 22 Nov 2019

HAL is a multi-disciplinary open access archive for the deposit and dissemination of scientific research documents, whether they are published or not. The documents may come from teaching and research institutions in France or abroad, or from public or private research centers.
L'archive ouverte pluridisciplinaire HAL, est destinée au dépôt et à la diffusion de documents scientifiques de niveau recherche, publiés ou non, émanant des établissements d'enseignement et de recherche français ou étrangers, des laboratoires publics ou privés. 


\title{
General Analytical Magnetic Model for Partitioned-Stator Flux-Reversal Machines with Four Types of Magnetization Patterns
}

\author{
A.A. Vahaj, A. Rahideh, T. Lubin, Member, IEEE
}

\begin{abstract}
A Partitioned Stator-Flux Reversal Permanent Magnet Machine (PS-FRPMM) is a new combination of a stator PM machine and a magnetically geared machine and has the specifications of both machines in terms of robust structure and torque density. In this paper a comprehensive 2-D analytical model is developed for PS-FRPMM based on subdomain technique. The presented model has the capability to accurately and quickly investigate the effects of design parameters on the machine performance. The 2-D analytical model is evaluated on two case studies with 12 stator teeth and 10 rotor poles, and 18 stator teeth and 13 rotor poles, with four different magnetization patterns. The influences of various design parameters such as the rotor slot width, slot opening width and the segment ratio of the PMs in the 2-segment magnetization pattern have been investigated on the quantities such as the instantaneous torque, torque ripple, Unbalanced Magnetic Force (UMF) and Electromotive Force (EMF). For evaluating the presented analytical model, 2-D Finite Element Method (FEM) with and without saturation effects has been used. The comparative study between the analytical and numerical models shows good agreement. Finally, a 3-D FEM has been used and the results of 2$D$ analytical model and 3-D FEM are compared in term of the accuracy and computational time. The results show that the presented model has lower computational time compared to the 2$D$ and 3-D FE method, while its accuracy is acceptable under different circumstances such as saturation.
\end{abstract}

Index Terms - Analytical model, Maxwell equations, Separation of variable technique, Sub-domain technique

\section{INTRODUCTION}

$\mathrm{P}$ ARTITIONED stator machines are a new generation of electrical machines in which the stator is split in two parts (PM stator and armature stator). These machines originated from a combination of the Flux Switching (FS) [1-2] and magnetically geared machines [3-5] and they offer the advantages of both machines. Therefore, a partitioned stator machine is a high performance electric machine with overload protection and high torque density per copper losses. They can be used in many applications such as power generation and electric propulsion [6,7].

Different kinds of PM stator machines are shown in Fig. 1. In the concepts of Flux Reversal (FR) (Fig. 1 (a)) [8], Switched Flux (SF) (Fig. 1 (b)) [9] and Doubly Salient (DS) (Fig. 1 (c)) [10] machines, stationary PMs are used, respectively, on the

AmirAbbas Vahaj is with the Department of Electrical and Electronics Engineering, Shiraz University of Technology, Shiraz 13876-71557, I. R. Iran (e-mail: a.vahaj@sutech.ac.ir).

Akbar Rahideh is with the Department of Electrical and Electronics Engineering, Shiraz University of Technology, Shiraz 13876-71557, I. R. Iran (e-mail: rahideh@sutech.ac.ir). (Corresponding) stator pole-shoes, between the stator teeth and in the stator yoke. These machines have a robust structure which makes them suitable for high-speed applications. Other configurations of stationary PM machines are Partitioned Stator (PS) machines, inspired from conventional stationary PM machines, e.g. FR, SF and DS, and magnetically geared machines. This paper focuses on partitioned stator-flux reversal permanent magnet machines (PS-FRPMMs).

This machine has two stators: one for the armature winding and the other for PMs. A salient rotor is located between the two stators. By separating the armature winding and stationary PMs, the space for the PM and armature winding increases, the motor copper losses decrease, heat is easily dissipated, PMs are kept away from the winding high-temperature zone, and the risk of the PM demagnetization is reduced. Consequently, PSFRPMM compared with the conventional FRM and conventional PM machines, shows better performance and higher torque density per copper losses [1,2], [6,7], [11-17].

\begin{tabular}{|c|c|c|}
\hline Electrical & $\Rightarrow$ Partitioned stator & Flux Reversal (FR) \\
\hline machine with & $\rightarrow$ Flux Reversal (FR) & Switched Flux (SF) \\
\hline stationary & $\Rightarrow$ Switched Flux (SF) & $\rightarrow$ Doubly Salient (DS) \\
\hline PMs & $\Rightarrow$ Doubly Salient(DS) & \\
\hline
\end{tabular}

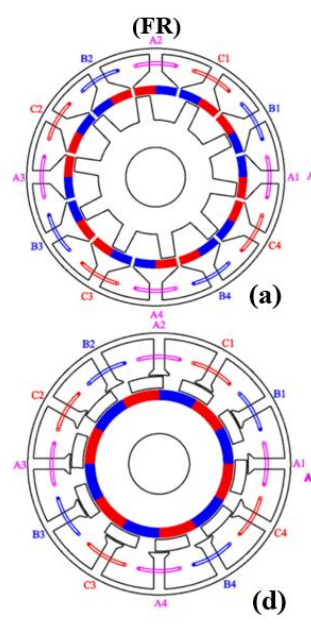

(PS-FR)
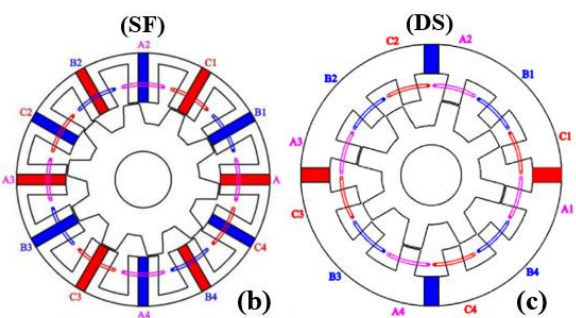

Fig.1. Classification of electric machines with stationary PMs [7]

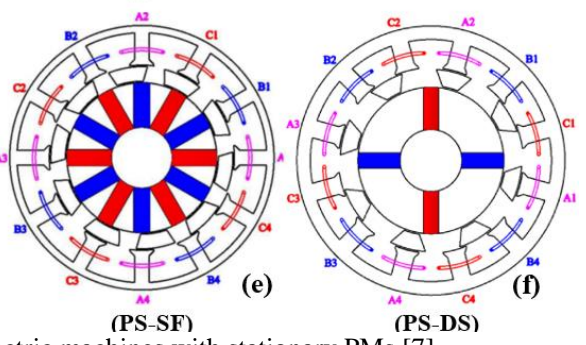

[7].

Thierry Lubin is with the Groupe de Recherche en Electrotechnique et Electronique de Nancy, University of Lorraine, 54506 Nancy, France (e-mail: thierry.lubin@green.uhp-nancy.fr). 
The analyses of the performance of PS machines have been done in [6,7], [11], [16,17]. PS machines are compared with stationary PM machines [7], [11, 12] with different magnet topologies [13,14] and different winding configurations [15] based on finite element analyses and prototype.

FEM is among the widely used techniques to analyze any electromagnetic system. Although FEM is accurate and complex geometries and nonlinearity can be incorporated by this method, it has normally higher execution time compared to the analytical methods [18].

This drawback can be solved by using analytical methods. The sub-domain method, which is the most accurate method among 2-D analytical models, is based on the analytical solution of Maxwell's equations in 2-D coordinate system [1843]. 2-D analytical model is not only fast but also gives physical insight to the problem.

Various 2-D analytical models have been presented for different types of electrical machines such as rotary with inner rotor [18,22,23,25], [27-40] or outer rotor [21,24,41], planar [42] and axial machines [43], to obtain electromagnetic quantities such as electromagnetic torque or force, inductances, induced voltage and core losses [21,29,31,39]. In some papers, the presented 2-D analytical models are employed to optimally design an electric machine [23, 32,35].

It is noteworthy that although the basic principle of 2-D analytical models is similar in all electromagnetic devices, the general/particular solutions in each sub-domain and the resultant equations from imposing the boundary conditions may vary from case to case. As example, the geometry of the presented machines in $[4,5]$, and $[19,20]$ may have similarities, but actually they have basic differences in number of subdomains, geometry specially rotating parts and number/kind of the boundary conditions which are the basis of this method.

The main contribution of this paper is the development of a 2-D analytical model for PS-FRPM machines with inner surface mounted PMs, with four types of magnetization patterns. To the best of authors' knowledge, this 2-D analytical model is not presented in the literature.

Based on the magnetic field calculation, the mutual torque, cogging torque, reluctance torque, unbalanced magnetic force, EMF and inductances are computed. The analytical results are compared with those of 2-D FEM to evaluate the accuracy of the proposed analytical model and the execution time in each method is presented. Then the effects of different rotor slot widths, stator slot-opening widths and segment ratios of PMs in the two-segment magnetization pattern, on the instantaneous torque and torque ripple are investigated. Also the effects of saturation on the instantaneous torque are investigated.

This paper is organized as follows: in section II, the machine topology and operation is explained. Sections III and IV are dedicated to the 2-D analytical model and calculations of the quantities. The results are presented in section V and VI, then discussed in section VII. Finally, the paper is concluded in section VIII.

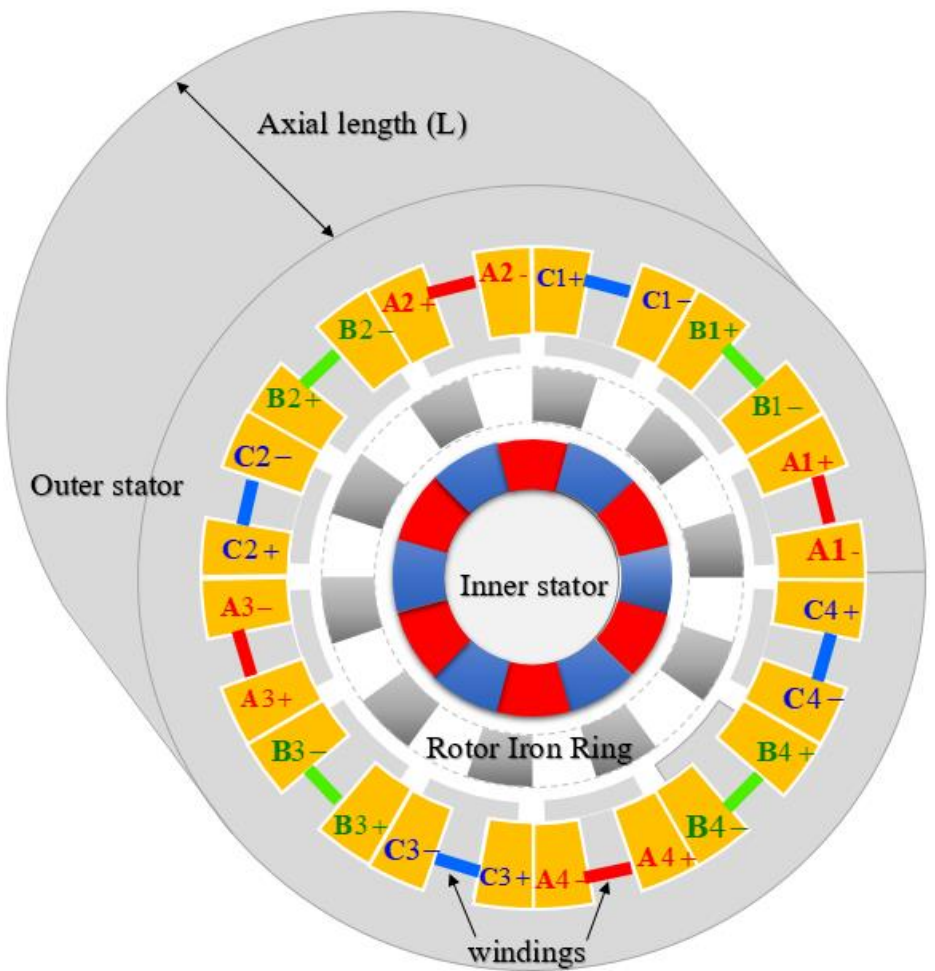

Fig. 2. Flux reversal Partitioned stator machine with inner stationary PMs.

\section{STRUCTURE AND OPERATION OF PARTITIONED STATOR MACHINES}

\section{A. Structure}

PS-FRPM machines have two separate stators: e.g. an inner stator including PM poles and an outer stator accommodating the armature windings. The rotor of PS-FRPM machines consists of iron poles, which is sandwiched between the two stators, as shown in Fig. 2. Also, the number of PMs are equal to the number of the stator teeth and the edge of the north pole and south pole of the PMs have been adjusted to be aligned with the middle of the outer stator teeth. The number of rotor pole can be any integer number except the phase number and its multiples [17].

\section{B. Operation principle}

The operation principle of PS-FRPM machines is to some extent similar to coaxial magnetic gears [3-5] or magnetically geared brushless PM machines [7,16]; their function is based on the modulation of the magnetic field by the iron-poles. Hence, in order to develop the maximum electromagnetic torque, the number of PM pole-pairs $(P)$, the number of rotor iron poles $\left(N_{r}\right)$ and the number of armature pole-pairs $\left(P_{s}\right)$ must obey the following relation [4]:

$$
P+P_{s}=N_{r}
$$

Also the relation between the electromagnetic torque produced by the armature winding $\left(T_{s}\right)$, transmitted torque to the rotor $\left(T_{r}\right)$, number of rotor poles $\left(N_{r}\right)$, number of armature winding pole-pairs $\left(P_{s}\right)$ and rotational speed of the rotor $\left(\omega_{r}\right)$ in RPM and rotational speed of the armature field $\left(\omega_{s}\right)$ is as follows:

$$
\frac{T_{r}}{T_{s}}=\frac{N_{r}}{P_{s}}=\frac{\omega_{s}}{\omega_{r}}
$$


Hence the required armature winding frequency $(f)$ to achieve predefined rotational speed of the rotor will be obtained as follows:

$\omega_{s}=\frac{120 f}{2 P_{s}} \longrightarrow f=\frac{\omega_{s} P_{s}}{60}$

Therefore, from (2) and (3):

$f=\frac{\omega_{r} N_{r}}{60}$

\section{2-D ANALYTIC MODEL}

The procedure of extracting the 2-D analytical magnetic model for electric machines is summarized in Fig. 3.

\begin{tabular}{|c|c|}
\hline Assumption & \\
\hline \multicolumn{2}{|c|}{ Creating sub-regions according to materials and shape } \\
\hline 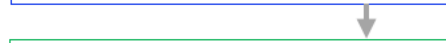 & \\
\hline \multicolumn{2}{|c|}{$\begin{array}{l}\text { Extracting the partial differential equation of each } \\
\text { sub-region according to Maxwell's equations }\end{array}$} \\
\hline$\downarrow$ & \\
\hline Define boundary conditions ba & sed on sub-regions \\
\hline 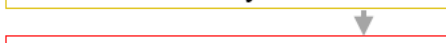 & \\
\hline Extracting Fourier series of $t$ & ne magnetization \\
\hline$\downarrow$ & \\
\hline Extracting Fourier series of the & slot current density \\
\hline$t$ & \\
\hline Finding the general solution $\mathrm{f}$ & r each sub-region \\
\hline 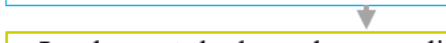 & \\
\hline $\begin{array}{l}\text { Implement the boundary condi } \\
\text { solutions to obtain integra }\end{array}$ & $\begin{array}{l}\text { ions to the general } \\
1 \text { coefficients }\end{array}$ \\
\hline$\frac{\Downarrow}{\text { Validation }}$ & \\
\hline
\end{tabular}

Fig. 3. Procedure of extracting 2-D analytical model

Each step is explained in the following sub-sections.

\section{A. Assumptions and geometry}

The following assumptions are made:

1) The end effects are neglected.

2) Ferromagnetic parts including the inner and outer stator back irons, stator teeth, and rotor pole-pieces have infinite permeability.

According to the geometry and materials, the whole problem is divided into six sub-domains as listed in Table I.

\begin{tabular}{lll}
\multicolumn{2}{c}{ TABLE I THE DEFINITIONS OF SUB-DOMAINS } \\
\hline \hline No. & Sub-domains & Superscripts \\
\hline 1 & PM (Inner Stator) & $m$ \\
2 & Inner air-gap & $i a$ \\
3 & Rotor slots & $r_{i}$ \\
4 & Outer air-gap & $o a$ \\
5 & Stator slot-openings & $s o_{j}$ \\
6 & Stator slots & $s_{j}$ \\
\hline \hline
\end{tabular}

$i=1,2, \ldots, N_{r}, j=1,2, \ldots, N_{s}$ where $N_{r}$ and $N_{s}$ are the number of the rotor slots and stator slots respectively.

As evident from Fig. 4, relations (5), (7) and (9) can be respectively expressed for the rotor slots, stator slots and slotopenings:

$$
\begin{aligned}
& \theta_{r_{i}}=\frac{-\beta}{2}+\frac{2 \pi}{N_{r}} i+\omega_{r} t+\theta_{r 0}, \quad i=1,2, \ldots, N_{r} \\
& \beta=\beta^{\prime} \tau_{r} \quad, \quad \tau_{r}=2 \pi / N_{r} \\
& \theta_{s_{j}}=\frac{-\delta}{2}+\frac{2 \pi}{N_{s}} j+\theta_{s 0}, \quad j=1,2, \ldots, N_{s} \\
& \delta=\delta^{\prime} \tau_{s} \quad, \quad \tau_{s}=2 \pi / N_{s} \\
& \theta_{s o_{j}}=\frac{-\sigma}{2}+\frac{2 \pi}{N_{s}} j+\theta_{s o 0}, \quad j=1,2, \ldots, N_{s} \\
& \sigma=\sigma^{\prime} \tau_{s}
\end{aligned}
$$

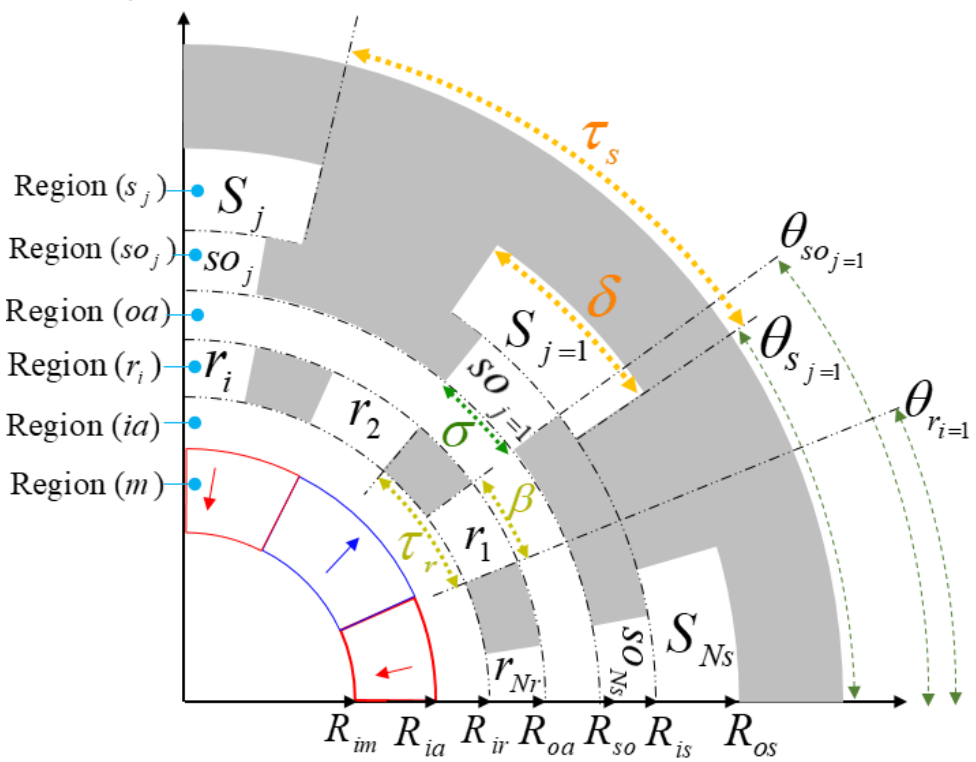

Fig. 4. Graphical annotation of the presented machine

where $\omega_{r}$ is the rotor angular velocity, $t$ is the time, $\theta_{r 0}$ is the initial rotor position, $\tau_{r}$ is the rotor slot pitch, $\beta$ is the span angle of the rotor slots, $\beta^{\prime}$ is the ratio of the rotor slot span angle and the rotor slot pitch, $\tau_{s}$ is the stator slot pitch, $\delta$ is the span angle of the stator slots, $\delta^{\prime}$ is the ratio of the stator slot span angle and the stator slot pitch, $\sigma$ is the span angle of the stator slot-openings, and $\sigma^{\prime}$ is the ratio of the stator slotopening span angle and the stator slot pitch. Also $\theta_{s 0}$ and $\theta_{s o 0}$ are the reference positions of slots and slot-openings as depicted in Fig. 4.

\section{B. Governing equations in each sub-regions}

The Poisson equations for the inner stator PMs, (11), and the outer stator slots, (12), and the Laplace equations (13) for the inner and outer air-gap sub-regions, stator slot-openings and rotor slots are obtained.

$$
\begin{aligned}
& -\frac{1}{r} \frac{\partial}{\partial r}\left(r \frac{\partial A_{z}^{m}}{\partial r}\right)-\frac{1}{r^{2}} \frac{\partial^{2} A_{z}^{m}}{\partial \theta^{2}}=\frac{\mu_{0}}{r}\left(\frac{\partial}{\partial r}\left(r M_{\theta}^{m}\right)-\frac{\partial M_{r}^{m}}{\partial \theta}\right) \\
& -\frac{1}{r} \frac{\partial}{\partial r}\left(r \frac{\partial A_{z}^{s_{j}}}{\partial r}\right)-\frac{1}{r^{2}} \frac{\partial^{2} A_{z}^{s_{j}}}{\partial \theta^{2}}=\mu_{0} \mu_{r} J_{z}^{s_{j}} \\
& -\frac{1}{r} \frac{\partial}{\partial r}\left(r \frac{\partial A_{z}^{x}}{\partial r}\right)-\frac{1}{r^{2}} \frac{\partial^{2} A_{z}^{x}}{\partial \theta^{2}}=0, x=i a, o a, r_{i}, s o_{j}
\end{aligned}
$$


where $A_{z}$ and $J_{z}^{s_{j}}$ are respectively the axial component of the magnetic vector potential and current density. Also, $M_{r}^{m}$ and $M_{\theta}^{m}$ are the radial and tangential components of the magnetization vector.

\section{Boundary and interface conditions}

The interface conditions at the boundary of any two neighboring sub-domains indicated by $x$ and $x+$, are $A_{z}^{x}=A_{z}^{x+}$ and $H_{\theta}^{x}=H_{\theta}^{x+}$, as listed in Table II. Also, Fig. 5 illustrates the boundary conditions in the rotor and stator slots. The relation between the magnetic flux density vector, $\mathbf{B}$, and the magnetic field intensity vector, $\mathbf{H}$, in the magnet region is as follows [39]:

$$
\mathbf{B}=\mu_{0} \mu_{r} \mathbf{H}+\mu_{0} \mathbf{M}
$$

where $\mathbf{M}$ is the magnetization vector.

\section{Extracting the Fourier series of PM magnetization pattern}

The magnetization vector in 2-D polar coordinates is as follows:

$$
\mathbf{M}=M_{r}^{m} \mathbf{r}+M_{\theta}^{m} \boldsymbol{\theta}
$$

where $\mathbf{r}$ and $\boldsymbol{\theta}$ are respectively the unit vectors in the radial and tangential directions. Information of the four types of the magnetization patterns with the radial and tangential components have been represented in Fig. 6. The radial and tangential components of the magnetization vector are expressed by their Fourier series expansions, as follows:

$$
M_{r}^{m}=\sum_{h=1}^{\infty}\left(M_{r h}^{m} \cos (h P \theta)+N_{r h}^{m} \sin (h P \theta)\right)
$$

$$
M_{\theta}^{m}=\sum_{h=1}^{\infty}\left(M_{\theta h}^{m} \cos (h P \theta)+N_{\theta h}^{m} \sin (h P \theta)\right)
$$

where $P$ is the number of the pole-pairs and $h$ is the number of harmonics. It is required to determine $M_{r h}^{m}$ and $N_{r h}^{m}$, which are the Fourier series coefficients of the radial component of the magnetization vector.

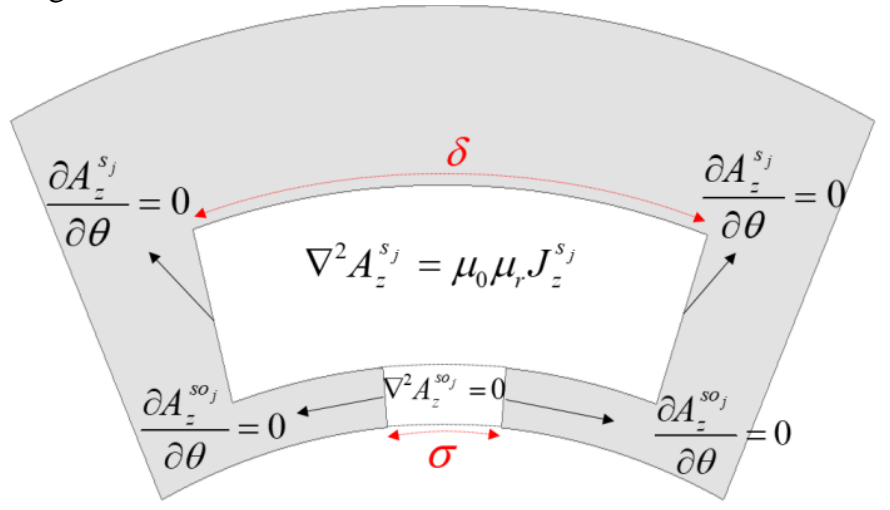

(a)

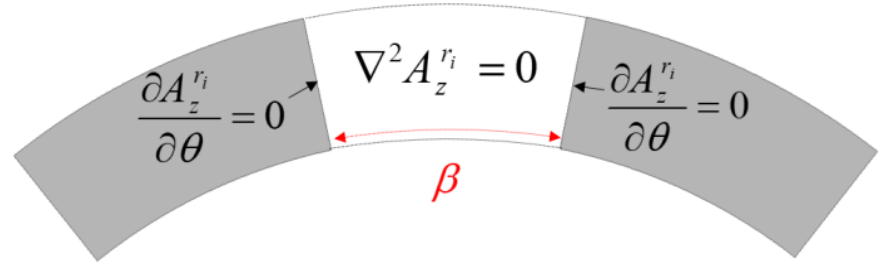

(b)

\begin{tabular}{|c|c|c|c|c|c|}
\hline Sub-Region $(x)$ & Sub-Region $(x+)$ & Boundary/Interface condition & Interface & Applied range & \\
\hline \multirow{3}{*}{$m$} & $\begin{array}{l}\text { Inner stator back } \\
\text { iron }\end{array}$ & $H_{\theta}^{m}(r, \theta)=0$ & $r=R_{i m}$ & $-\pi \leq \theta \leq \pi$ & (14) \\
\hline & \multirow{2}{*}{$i a$} & $A_{z}^{m}(r, \theta)=A_{z}^{i a}(r, \theta)$ & \multirow{2}{*}{$r=R_{i a}$} & \multirow{2}{*}{$-\pi \leq \theta \leq \pi$} & (15) \\
\hline & & $H_{\theta}^{m}(r, \theta)=H_{\theta}^{i a}(r, \theta)$ & & & (16) \\
\hline \multirow[b]{2}{*}{ ia } & $r_{i}$ & $A_{z}^{i a}(r, \theta)=A_{z}^{r_{i}}(r, \theta)$ & \multirow[b]{2}{*}{$r=R_{i r}$} & \multirow[b]{2}{*}{$\theta_{r_{i}} \leq \theta \leq \theta_{r_{i}}+\beta, i=1,2, \ldots, N_{r}$} & (17) \\
\hline & All the $r_{i}$ & $H_{\theta}^{i a}(r, \theta)=\sum_{i=1}^{N_{r}} H_{\theta}^{r_{i}}(r, \theta)$ & & & (18) \\
\hline \multirow{4}{*}{$o a$} & $r_{i}$ & $A_{z}^{o a}(r, \theta)=A_{z}^{r_{i}}(r, \theta)$ & \multirow[b]{2}{*}{$r=R_{o a}$} & \multirow[b]{2}{*}{$\theta_{r_{i}} \leq \theta \leq \theta_{r_{i}}+\beta, i=1,2, \ldots, N_{r}$} & (19) \\
\hline & All the $r_{i}$ & $H_{\theta}^{o a}(r, \theta)=\sum_{i=1}^{N_{r}} H_{\theta}^{r_{i}}(r, \theta)$ & & & (20) \\
\hline & $\mathrm{SO}_{j}$ & $A_{z}^{o a}(r, \theta)=A_{z}^{s o_{j}}(r, \theta)$ & \multirow[b]{2}{*}{$r=R_{s o}$} & \multirow[b]{2}{*}{$\theta_{s o_{j}} \leq \theta \leq \theta_{s o_{j}}+\sigma, j=1,2, \ldots, N_{s}$} & (21) \\
\hline & All the $s o_{j}$ & $H_{\theta}^{o a}(r, \theta)=\sum_{j=1}^{N_{s}} H_{\theta}^{s o_{j}}(r, \theta)$ & & & $(22)$ \\
\hline \multirow{2}{*}{$s o_{j}$} & \multirow{2}{*}{$s_{j}$} & $A_{z}^{s o_{j}}(r, \theta)=A_{z}^{s_{j}}(r, \theta)$ & \multirow{2}{*}{$r=R_{i s}$} & \multirow{2}{*}{$\theta_{s_{j}} \leq \theta \leq \theta_{s_{j}}+\delta, j=1,2, \ldots, N_{s}$} & (23) \\
\hline & & $H_{\theta}^{s o_{j}}(r, \theta)=H_{\theta}^{s_{j}}(r, \theta)$ & & & $(24)$ \\
\hline$s_{j}$ & $\begin{array}{l}\text { Outer stator back } \\
\text { iron }\end{array}$ & $H_{\theta}^{s_{j}}(r, \theta)=0$ & $r=R_{o s}$ & $\theta_{s_{j}} \leq \theta \leq \theta_{s_{j}}+\delta, j=1,2, \ldots, N_{s}$ & $(25)$ \\
\hline
\end{tabular}

Fig. 5. (a) stator slot and slot-opening with the boundary conditions; (b) rotor slot with the boundary conditions.

TABLE II BOUNDARY AND INTERFACE CONDITIONS 


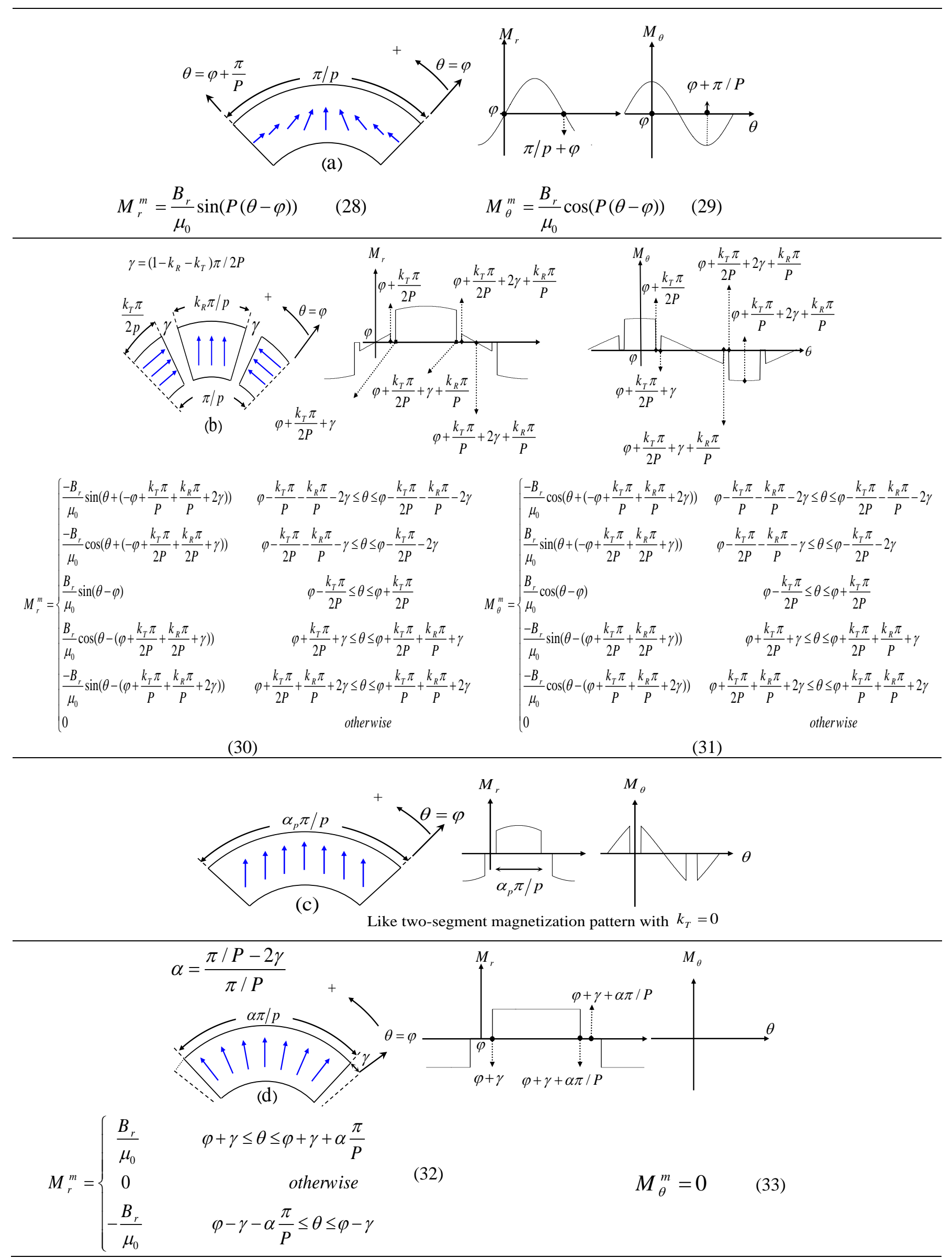

Fig. 6. Four types of the magnetization patterns with their functions (a)Ideal Halbach (b) Two-segments Halbach (c) Parallel (d) Radial 
Also $M_{\theta h}^{m}$ and $N_{\theta h}^{m}$ are the Fourier series coefficients of the tangential component of the magnetization vector.

$$
\begin{aligned}
& M_{r h}^{m}=\frac{P}{\pi} \int_{\varphi-\frac{\pi}{P}}^{\varphi+\frac{\pi}{P}} M_{r}^{m} \cos (h P \theta) d \theta \\
& N_{r h}^{m}=\frac{P}{\pi} \int_{\varphi-\frac{\pi}{P}}^{\varphi+\frac{\pi}{P}} M_{r}^{m} \sin (h P \theta) d \theta \\
& M_{\theta h}^{m}=\frac{P}{\pi} \int_{\varphi-\frac{\pi}{P}}^{\varphi+\frac{\pi}{P}} M_{\theta}^{m} \cos (h P \theta) d \theta \\
& N_{\theta h}^{m}=\frac{P}{\pi} \int_{\varphi-\frac{\pi}{P}}^{\varphi+\frac{\pi}{P}} M_{\theta}^{m} \sin (h P \theta) d \theta
\end{aligned}
$$

where $\varphi$ is the reference position of the PMs. It is required to adjust the borderline between the north and south poles of the PMs to be aligned with the middle of the outer stator teeth as depicted in Fig. 2. The solution of each integral depends only on the magnetization pattern.

\section{E. Extracting the Fourier series of current density}

The current density in each slot (Fig. 7), can be represented as the following Fourier series expansion:

$$
J^{s_{j}}=J_{0}^{s_{j}}+\sum_{v=1}^{\infty}\left[J_{v}^{s_{j}} \cos \left(\frac{v \pi}{\delta}\left(\theta-\theta_{s_{j}}\right)\right]\right.
$$

where $J_{0}^{s_{j}}, J_{v}^{s_{j}}$ are the Fourier series coefficients obtained as follows:

$$
\begin{aligned}
& J_{0}^{s_{j}}(t)=\frac{1}{2 \delta} \int_{\theta_{s_{j}}-\delta}^{\theta_{s_{j}}+\delta} J_{z}^{s_{j}} d \theta=\frac{J_{l}^{s_{j}}(t)+J_{r}^{s_{j}}(t)}{2} \\
& J_{v}^{s_{j}}(t)=\frac{1}{\delta} \int_{\theta_{s_{j}}-\delta}^{\theta_{s_{j}}+\delta} J_{z}^{s_{j}} \cos \left(\frac{v \pi}{\delta}\left(\theta-\theta_{s_{j}}\right)\right) d \theta=\frac{J_{l}^{s_{j}}(t)-J_{r}^{s_{j}}(t)}{v \pi / 2} \sin (v \pi / 2)
\end{aligned}
$$

where $J_{l}^{s_{j}}$ and $J_{r}^{s_{j}}$ are the current density of the left and right coil-sides in slot $j$ at an instant of time.

The current density in each slot depends on the winding configuration. In this investigation, the winding configuration is a two-layer concentrated type; i.e. two legs of two coils are placed in each slot, as depicted in Fig. 7.

\section{F. General and particular solutions of sub-regions}

By using the separation of variable technique, the general solution including particular solution for each sub-domain are represented in Table III where $n, k, u$ and $v$ are the harmonic number respectively in PM and air-gaps, rotor slots, slot opening and slot sub-regions. $N, K, U$ and $V$ are the corresponding maximum harmonic number in the abovementioned sub-regions.
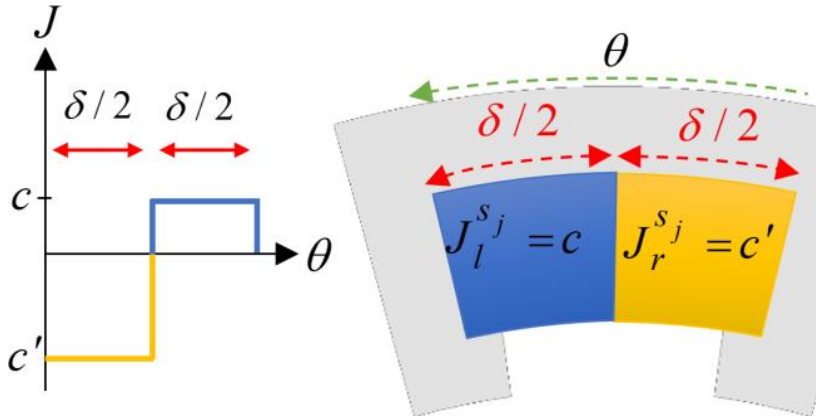

Fig. 7. A stator slot and the current density in a specific time

$$
\text { Also } \hat{a}_{n}^{m}, \hat{b}_{n}^{m}, \hat{c}_{n}^{m}, \hat{d}_{n}^{m}, a_{0}^{i a}, \hat{a}_{n}^{i a}, \hat{b}_{n}^{i a}, \hat{c}_{n}^{i a}, \hat{d}_{n}^{i a}, a_{0}^{r_{i}}, b_{0}^{r_{i}}, \hat{a}_{k}^{r_{i}}, \hat{b}_{k}^{r_{i}},
$$$$
\hat{a}_{n}^{o a}, b_{n}^{o a}, \hat{c}_{n}{ }^{o a}, \hat{d}_{n}^{o a}, a_{0}^{s o_{j}}, b_{0}^{s o_{j}}, \hat{a}_{u}^{s o_{j}}, b_{u}^{s o_{j}}, a_{0}^{s_{j}}, b_{0}^{s_{j}}, \hat{a}_{v}^{s_{j}}, \hat{b}_{v}^{s_{j}} \text { are the }
$$
integral coeffcients and must be determined by using the boundary/interface conditions.

The particular solution of the PM sub-domain, as shown in (44), is obtained by substituting the defined particular solution in (11). Finally $K_{n 1}(r)$ and $K_{n 2}(r)$ are obtained in terms of the Fourier series expansion of the magnetization components as follows:

$$
\begin{aligned}
& k_{n 1}(r)= \begin{cases}\frac{-\mu_{0}\left(M_{\theta h}^{m}-h P N_{r h}^{m}\right)}{\left(1-n^{2}\right)} r & , n=h P, h=1,2,3, \ldots \\
\frac{-\mu_{0}}{2}\left(M_{\theta 1}^{m}-N_{r 1}^{m}\right) r \ln (r) & , n=P=1\end{cases} \\
& k_{n 2}(r)= \begin{cases}\frac{-\mu_{0}\left(N_{\theta h}^{m}+h P M_{r h}^{m}\right)}{\left(1-n^{2}\right)} r & , n=h P, h=1,2,3, \ldots \\
\frac{-\mu_{0}}{2}\left(N_{\theta 1}^{m}+M_{r 1}^{m}\right) r \ln (r) & , h=P=1\end{cases}
\end{aligned}
$$

Also, in order to determine $K_{0}(r)$ and $K_{v}(r)$ in the particular solution of the slot sub-domain, it is necessary to substitute (50) in (12); then instead of $J_{z}^{s_{j}}$ in (12), the Fourier series expansion of the current density in each slot is substituted. Therefore, $K_{0}(r)$ and $K_{v}(r)$ are obtained as follows:

$$
\begin{gathered}
K_{0}(r)=\frac{-\mu_{0}}{4} \mu_{r}^{s_{j}} J_{0}^{s_{j}} r^{2} \\
K_{v}(r)=\frac{\mu_{0} \mu_{r}^{s_{j}} J_{v}^{s_{j}} r^{2}}{\left(\frac{v \pi}{\delta}\right)^{2}-4}
\end{gathered}
$$

\section{G. Obtaining integral coefficients}

To obtain the integral coefficients, the boundary/interface conditions listed in Table II, along with (55) [5], are required.

$$
\left.\int_{0}^{2 \pi} H_{\theta}^{m}\right|_{r=R_{i a}} d \theta=\left.\int_{0}^{2 \pi} \sum_{i=1}^{N_{r}} H_{\theta}^{r_{i}}\right|_{r=R_{i r}} d \theta
$$

The resulted equations, after imposing the boundary /interface conditions are given in the appendix.

\section{Calculation OF QuANTITIES}

\section{A. Air-gap flux density}

From the analytically calculated magnetic vector potential in each of the sub-domains, the radial and tangential components 
TABLE III GENERAL AND PARTICULAR SOLUTION OF EACH SUB-DOMAIN

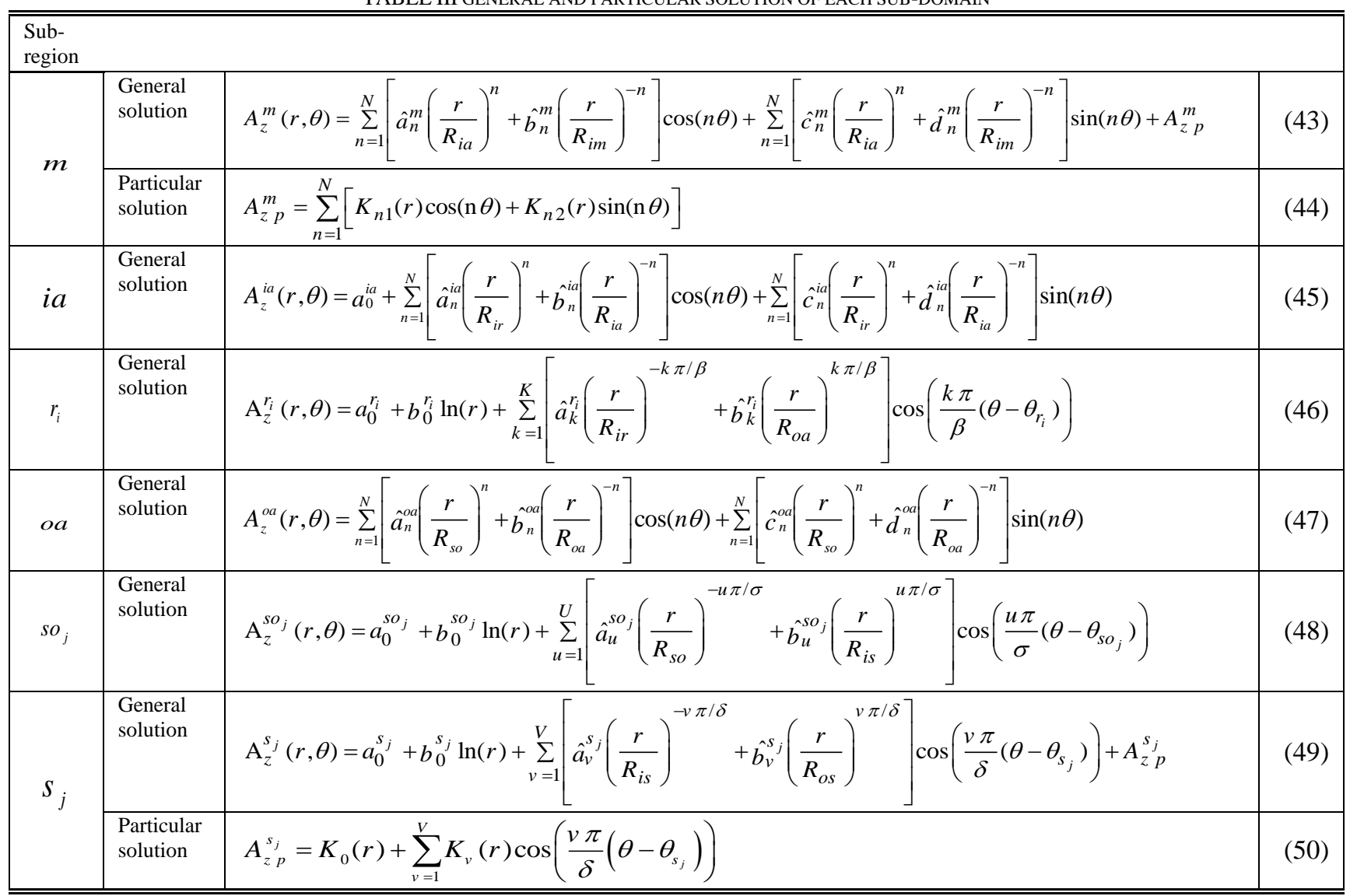

of the magnetic flux density vector can be analytically computed using the following relations:

$$
B_{r}(r, \theta)=\frac{1}{r} \frac{\partial A_{z}}{\partial \theta} \quad(56), \quad B_{\theta}(r, \theta)=-\frac{\partial A_{z}}{\partial r}(57)
$$

For the sake of brevity, only the radial and tangential components of the magnetic flux density vectors in the inner and outer air-gap sub-domains are represented in (58)-(61).

\section{B. Electromagnetic torque}

The developed instantaneous electromagnetic torque can be computed using the Maxwell stress tensor that consists of the mutual, cogging and reluctance torque components.

$$
\begin{aligned}
& T_{\text {in }}=\frac{L R_{m 1}^{2}}{\mu_{0}} \int_{0}^{2 \pi} B_{r}^{i a}\left(R_{m 1}, \theta\right) \cdot B_{\theta}^{i a}\left(R_{m 1}, \theta\right) \cdot d \theta \\
& T_{\text {out }}=\frac{L R_{m 2}^{2}}{\mu_{0}} \int_{0}^{2 \pi} B_{r}^{o a}\left(R_{m 2}, \theta\right) \cdot B_{\theta}^{o a}\left(R_{m 2}, \theta\right) \cdot d \theta
\end{aligned}
$$

where $T_{\text {in }}$ and $T_{\text {out }}$ are respectively the part of the developed torques in the inner and outer air-gap sub-domains, $L$ is the axial length of the machine, $\mathrm{R}_{m_{1}}=\left(R_{i a}+R_{i r}\right) / 2$ and $\mathrm{R}_{m_{2}}=\left(R_{o a}+R_{s o}\right) / 2$.

Finally, the exerted torque to the rotor is obtained as follows:

$$
T=T_{\text {out }}-T_{\text {in }}
$$

\section{Unbalanced magnetic force}

The total unbalance magnetic force (UMF), can be obtained using the Maxwell stress tensor calculated in the inner and outer air-gap sub-domains. In this study, it is assumed the rotor has no eccentricity and it is perfectly centered in the annular space between the two stators.

$$
\mathbf{U M F}=\mathbf{F}^{i a}+\mathbf{F}^{o a}
$$

where $\mathbf{F}^{i a}$ and $\mathbf{F}^{o a}$ are respectively the vector forces calculated in the inner and outer air-gap sub-domains. First, the radial and

$$
\begin{aligned}
& B_{r}^{i a}(r, \theta)=\sum_{n=1}^{N}\left(\hat{a}_{n}^{i a} \frac{-n}{r}\left(\frac{r}{R_{i r}}\right)^{n}+\hat{b}_{n}^{i a} \frac{-n}{r}\left(\frac{r}{R_{i a}}\right)^{-n}\right) \sin (n \theta)+\sum_{n=1}^{N}\left(\hat{c_{n}^{i a}} \frac{n}{r}\left(\frac{r}{R_{i r}}\right)^{n}+\hat{d}_{n}^{i a} \frac{n}{r}\left(\frac{r}{R_{i a}}\right)^{-n}\right) \cos (n \theta) \\
& B_{\theta}^{i a}(r, \theta)=\sum_{n=1}^{N}\left(\hat{a}_{n}^{i a} \frac{-n}{r}\left(\frac{r}{R_{i r}}\right)^{n}+\hat{b}_{n}^{i a} \frac{n}{r}\left(\frac{r}{R_{i a}}\right)^{-n}\right) \cos (n \theta)+\sum_{n=1}^{N}\left(\hat{c}_{n}^{i a} \frac{-n}{r}\left(\frac{r}{R_{i r}}\right)^{n}+\hat{d}_{n}^{i a} \frac{n}{r}\left(\frac{r}{R_{i a}}\right)^{-n}\right) \sin (n \theta) \\
& B_{r}^{o a}(r, \theta)=\sum_{n=1}^{N}\left(\hat{a}_{n}^{o a} \frac{-n}{r}\left(\frac{r}{R_{s o}}\right)^{n}+\hat{b}_{n}^{o a} \frac{-n}{r}\left(\frac{r}{R_{o a}}\right)^{-n}\right) \sin (n \theta)+\sum_{n=1}^{N}\left(\hat{c}_{n}^{o a} \frac{n}{r}\left(\frac{r}{R_{s o}}\right)^{n}+\hat{d}_{n}^{o a} \frac{n}{r}\left(\frac{r}{R_{o a}}\right)^{-n} \cos (n \theta)\right. \\
& B_{\theta}^{o a}(r, \theta)=\sum_{n=1}^{N}\left(\hat{a}_{n}^{o a} \frac{-n}{r}\left(\frac{r}{R_{s o}}\right)^{n}+\hat{b}_{n}^{o a} \frac{n}{r}\left(\frac{r}{R_{o a}}\right)^{-n}\right) \cos (n \theta)+\sum_{n=1}^{N}\left(\hat{c}_{n}^{o a} \frac{-n}{r}\left(\frac{r}{R_{s o}}\right)^{n}+\hat{d}_{n}^{o a} \frac{n}{r}\left(\frac{r}{R_{o a}}\right)^{-n} \sin (n \theta)\right.
\end{aligned}
$$


tangential components of the local tractions $\left(\mathrm{N} / \mathrm{m}^{2}\right)$ in the inner and outer air-gap sub-domains are calculated using the following expressions:

$$
\begin{aligned}
& f_{r}^{\chi}=\frac{1}{2 \mu_{0}}\left(\left(B_{r}^{\chi}\right)^{2}-\left(B_{\theta}^{\chi}\right)^{2}\right), \chi=i a, o a \\
& f_{\theta}^{\chi}=\frac{1}{\mu_{0}} B_{r}^{\chi} B_{\theta}^{\chi}
\end{aligned}
$$

where $B_{r}^{\chi}$ and $B_{\theta}^{\chi}$ are the radial and tangential components of the magnetic flux density vector in the inner or outer air-gap sub-domains. The radial and tangential components of the local tractions are converted to their corresponding $x$ and $y$ components as follows:

$$
\begin{aligned}
& f_{x}{ }^{x}=f_{r}{ }^{x} \cos (\theta)-f_{\theta}{ }^{x} \sin (\theta) \\
& f_{y}{ }^{x}=f_{r}{ }^{x} \sin (\theta)+f_{\theta}{ }^{x} \cos (\theta)
\end{aligned}
$$

Finally, the $x$ and $y$ components and also the modulus of the UMFs in the inner or outer air-gap sub-domains are computed as follows:

$$
\begin{aligned}
& F_{x}^{\chi}(t)=L \int_{-\pi}^{\pi} f_{x}^{\chi} r d \theta \\
& F_{y}^{\chi}(t)=L \int_{-\pi}^{\pi} f_{y}^{\chi} r d \theta \\
& |F(t)|=\sqrt{\left(F_{x}^{i a}(t)-F_{x}^{o a}(t)\right)^{2}+\left(F_{y}^{i a}(t)-F_{y}^{o a}(t)\right)^{2}}
\end{aligned}
$$

\section{D. $E M F$}

Since the windings are two-layer non-overlapping concentrated type, which means each coil is wound around each tooth, the flux linked to each coil can be computed by having the flux passing through the corresponding tooth. In this investigation, the back iron and the teeth are not among the active sub-domains and the flux passing through the teeth should be obtained indirectly from the magnetic flux of the surrounding active sub-domains. Therefore, to calculate the noload flux linkage, the magnetic flux due to PMs passing through each tooth is calculated from the summation of the flux over edges of the tooth, i.e. two edges in the slots, two edges in the slot-openings and an edge in the air-gap as depicted in Fig. 8. This procedure is mathematically represented as follows:

$$
\phi_{a f}^{\text {tooth }_{j}}=\phi_{a b}^{s_{j-1}}+\phi_{b c}^{s o_{j-1}}+\phi_{c d}^{o a}+\phi_{d e}^{s o_{j}}+\phi_{e f}^{s_{j}}
$$$$
\text { for } j=1,2, \ldots, N_{s}
$$

which leads to the following integration:

$$
\begin{aligned}
& \int \mathbf{B} \cdot \mathbf{d s}_{t o o t h_{j}}=\left.\int_{\theta_{s s l_{j-1}}+\delta}^{\theta_{s o_{j}-1}+\sigma} B_{r}^{s_{j-1}} r d \theta d z\right|_{r=R_{i s}}+ \\
& \left.\int_{R_{i s}}^{R_{s o}} B_{\theta}^{s o_{j-1}} d r d z\right|_{\theta=\theta_{s o o_{j-1}}+\sigma}+\left.\int_{\theta_{s o o_{j-1}}+\sigma}^{\theta_{s o_{j}}} B_{r}^{i a} r d \theta d z\right|_{r=R_{s o}} \\
& +\left.\int_{R_{s o}}^{R_{i s}} B_{\theta}^{s o_{j}} d r d z\right|_{\theta=\theta_{s o o_{j}}}+\left.\int_{\theta_{s o_{j}}}^{\theta_{s s l_{j}}} B_{r}^{s_{j}} r d \theta d z\right|_{r=R_{i s}}
\end{aligned}
$$

where

$$
j=1,2, \ldots, N_{s} \quad \text {, if } \quad(j-1)=0 \rightarrow(j-1)=N_{s}
$$

Having calculated the magnetic flux linkage of each coil, the EMF induced in that coil is easily computed using the Faraday

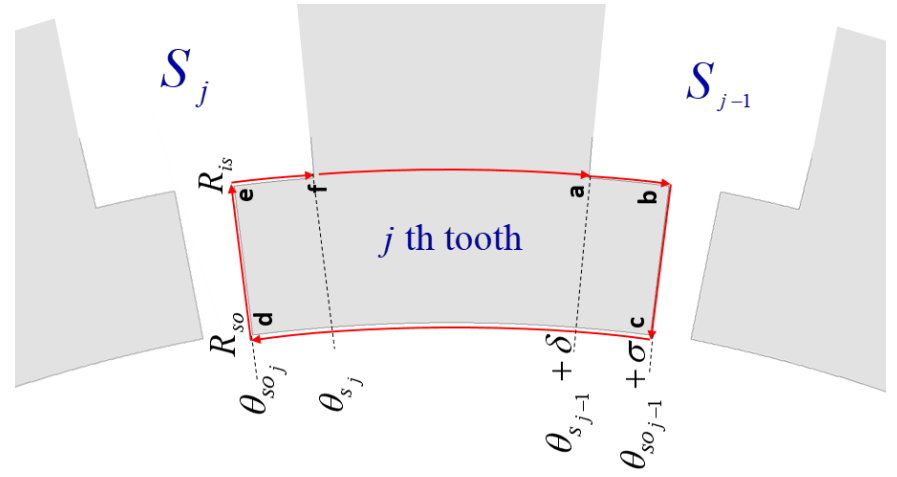

Fig. 8. A stator tooth and the integration path for flux linkage calculation.

law:

$$
E=-N_{t} \frac{d \phi}{d t}=-N_{t} \frac{d \phi}{d \theta} \frac{d \theta}{d t}=-N_{t} \omega \frac{d \phi}{d \theta}
$$

where $N_{t}$ is the number of turns per coil and $\omega$ is the angular velocity of the rotor in rad/s. Finally, depending on the coil connections in each phase, the phase EMF is obtained.

\section{E. Inductance}

To compute the self and mutual inductances, the magnetic flux due to armature current passing through each coil needs to be calculated. The procedure is similar to the magnetic flux linkage calculation for the EMF and the only difference is the origination of the magnetic flux. For the calculation of perphase self-inductance, the coils of that phase are excited by a constant current, and the flux linked by all coils of that phase is computed. The per-phase self-inductance is calculated by the following expression:

$$
L_{j j}=\frac{\lambda_{j}}{i_{j}}, \quad j=1,2,3
$$

where $\lambda_{j}$ is the summation of the flux linked by the coils of phase $j$, and $i_{j}$ is the current injected to phase $j$.

The mutual inductances between phases are calculated in a similar manner. If the coils of phase $j$ are excited and the flux linked by the coils of phase $i$ is obtained, the mutual inductance between phases $i$ and $j$ is calculated using the following expression:

$$
L_{i j}=\lambda_{i} / i_{j}, \quad i \neq j, \quad i=1,2,3, \quad j=1,2,3
$$

where $\lambda_{i}$ is the summation of the flux linked by the coils of phase $i$, and $i_{j}$ is the current of phase $j$.

\section{RESULTS OF THE FIRST CASE STUDY}

To evaluate the proposed 2-D analytical model, two case studies have been investigated. The parameters of the first case study have been listed in Table IV. The results of the analytical model are compared to those of FEM.

\section{A. Air-gap magnetic flux density}

Figs. 9 (a)-(d) show the radial and tangential components of the magnetic flux density due to both open circuit and armature reaction for the presented magnetization patterns, in the middle of the inner and outer air-gap sub-domains, where the position of the rotor is set to zero.

Also, the current density values of phase A, B and C, according to the injected currents to the phases (78)-(80), at $\mathrm{t}=0$, 
are respectively set to $-2.3443 \mathrm{~A} / \mathrm{mm}^{2}, 4.9968 \mathrm{~A} / \mathrm{mm}^{2}$ and $-2.6526 \mathrm{~A} / \mathrm{mm}^{2}$. Consider the following three phase sinusoidal armature current.

$$
\begin{aligned}
& i_{a}=i_{m} \sin \left(2 \pi f \times t+\phi_{0}\right) \\
& i_{b}=i_{m} \sin \left(2 \pi f \times t-2 \pi / 3+\phi_{0}\right) \\
& i_{c}=i_{m} \sin \left(2 \pi f \times t-4 \pi / 3+\phi_{0}\right)
\end{aligned}
$$

where $i_{m}$ is the maximum value of the current. $f$ is the current frequency and $\phi_{0}$ is the current initial temporal angle. The current density of each phase is obtained as follows:

$$
J_{\chi}=\frac{N_{t} i_{\chi}}{C S A \times F F} \quad, \quad \chi=a, b, c
$$

where $C S A$ is the cross sectional area of each coil in two-layer windings and is equal to $C S A=\frac{\pi \delta^{\prime}\left(R_{o s}^{2}-R_{i s}^{2}\right)}{2 N_{s}}=6.05 \times 10^{-5} \mathrm{~m}^{2}$ for the first case study and $N_{t}$ is the number of turns per coil and $F F$ is the filling factor. As evident from the figures, the analytical and numerical results are in good agreement, which shows the accuracy of the proposed 2-D analytical model for the case study.

\section{B. Torque}

Figs. 10 (a)-(c), show respectively the instantaneous torque, cogging torque and reluctance torque of the machine with different magnetization patterns, both analytically and numerically. The results show good agreement and the effects of the magnetization patterns on the instantaneous torque and torque ripple are illustrated. As evident from Fig. 10 (a), the machine with the radial magnetization pattern has the lowest value of the instantaneous torque. The machines with the ideal Halbach, two-segment Halbach and parallel magnetization patterns develop respectively, 24.04\%, $15.05 \%$, and $9.16 \%$, more average instantaneous torque compared to the machine with the radial magnetization pattern. The type of the magnetization pattern has significant effects on the torque ripple as evident from Fig 10 (b). The torque ripple is calculated by the difference between the maximum and minimum torque values divided by the average torque. The percentages of torque ripple for the machines equipped with the ideal Halbach, radial, parallel and two-segment Halbach magnetization patterns are respectively calculated as $2.45 \%, 9.36 \%, 9.44 \%$ and $10.64 \%$. Hence, the lowest torque ripple belongs to the machine with the ideal Halbach magnetization pattern and the highest one belongs to the two-segment Halbach magnetization pattern when $K_{T}=0.5$. Fig. 10 (c), shows the reluctance torque caused by the rotor saliency. The instantaneous torque results obtained from the proposed 2-D analytical model are shown in Fig. 10 (d-g) and compared with 3-D linear numerical method respectively under the ideal Halbach, two-segment Halbach, parallel and radial magnetization patterns where the materials in FEM are considered to be linear. As evident from Fig. 10 (d$\mathrm{g}$ ), the relative error between the proposed 2-D analytical model and 3-D FEM model is about $8.772 \%$ for ideal Halbach, $9.657 \%$ for two-segment Halbach, $10.06 \%$ for the parallel

\begin{tabular}{|c|c|c|}
\hline Parameters & Sym. & values \\
\hline Inner radius of $\mathrm{PMs}$ & $R_{i m}$ & $16 \mathrm{~mm}$ \\
\hline Inner radius of inner air-gap & $R_{i a}$ & $20 \mathrm{~mm}$ \\
\hline Inner radius of rotor & $R_{i r}$ & $20.8 \mathrm{~mm}$ \\
\hline Inner radius of outer air-gap & $R_{o a}$ & $24.8 \mathrm{~mm}$ \\
\hline Inner radius of slot-opening & $R_{s o}$ & $25.6 \mathrm{~mm}$ \\
\hline Inner radius of stator slots & $R_{i s}$ & $28 \mathrm{~mm}$ \\
\hline Outer radius of stator slots & $R_{o s}$ & $38 \mathrm{~mm}$ \\
\hline Axial length of motor & $L$ & $100 \mathrm{~mm}$ \\
\hline Remenance of PMs & $B_{r}$ & $1.2 \mathrm{~T}$ \\
\hline Number of inner stator pole-pairs & $P_{i}$ & 6 \\
\hline Number of rotor pole-pieces & $N_{r}$ & 10 \\
\hline Number of stator slots & $N_{s}$ & 12 \\
\hline Number of stator pole-pairs & $P_{s}$ & 4 \\
\hline Rotor mechanical speed & $\omega_{r}$ & 400rpm \\
\hline Maximum value of the current & $i_{m}$ & $8.4028 A$ \\
\hline Armature current frequency & $f$ & $66.67 \mathrm{~Hz}$ \\
\hline Initial angle for the armature current & $\phi_{0}$ & $-152.04^{\circ}$ \\
\hline Number of turns per coil & $N_{t}$ & 18 \\
\hline Rotor slot span angle to rotor slot pitch & $\beta^{\prime}$ & 0.5 \\
\hline Stator slot span angle to stator slot pitch & $\delta^{\prime}$ & 0.7 \\
\hline Stator slot-opening span angle to stator slot pitch & $\sigma^{\prime}$ & 0.2 \\
\hline Permeability of the slots & $\mu_{r}^{s_{j}}$ & 1 \\
\hline Filling factor of the slot & $F F$ & 0.5 \\
\hline Maximum number of harmonics used in sub-regions & $\begin{array}{l}N, K \\
U, V\end{array}$ & 150 \\
\hline
\end{tabular}
magnetization and $9.89 \%$ for the radial magnetization patterns. The discrepancy may be due to the neglecting of the end effect
TABLE IV PARAMETERS OF THE FIRST CASE STUDY

and/or mesh size in the 3-D FEM.

\section{Unbalanced magnetic forces, EMF and Inductances}

Fig. 11 (a) shows the no-load phase EMF waveforms obtained from the analytical and numerical models. The analytical and numerical results of the no-load EMF have conformity for presented case study. The maximum induced voltage caused by the ideal Halbach magnetization pattern is $9.138 \mathrm{~V}$. This value is $24.56 \%$ more than the maximum induced voltage by the radial magnetization pattern which is $7.336 \mathrm{~V}$. Also, the two-segment Halbach and parallel magnetization patterns respectively induce $15.74 \%$ and $9.24 \%$ more EMF, in comparison with the radial magnetization pattern.

The self-inductance of the first phase and the mutualinductance between the first, and two other phases are analytically calculated as shown in Fig. 11 (b) and compared to the corresponding results obtained from FEM. Because of the rotor saliency, the inductances are functions of the rotor angular position. Also the low saliency ratio results in a small variation of the inductances.

The local tractions exerted to the inner and outer surface of the rotor, and the unbalanced magnetic forces for the first case study by each of the magnetization patterns are depicted in Figs. 12 and 13. As evident, the value of the local traction for all of the magnetization patterns is very high; however, because the local traction modulus distribution is diagonally symmetric, as depicted in Figs. 12 and 13 (c), (d), (h), (i), the total UMF values 
are almost zero and have conformity with the results of FEM.

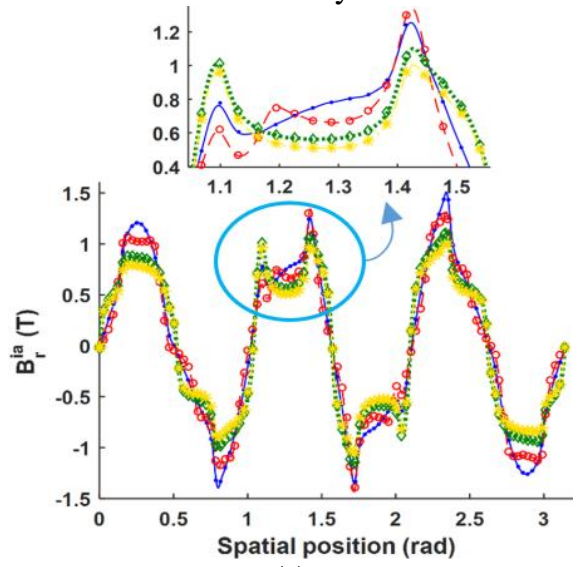

(a)

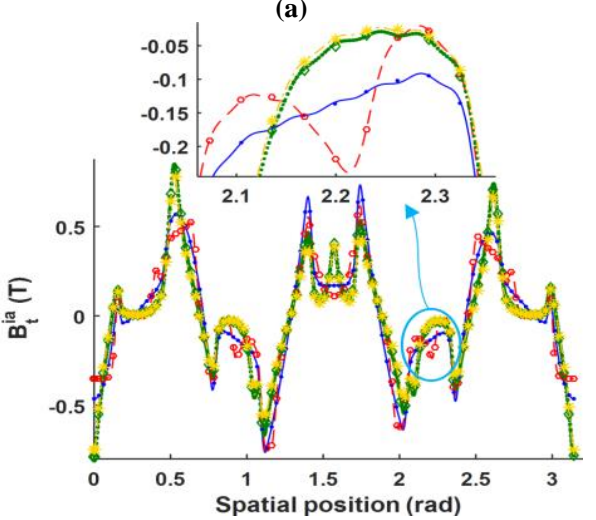

(b)

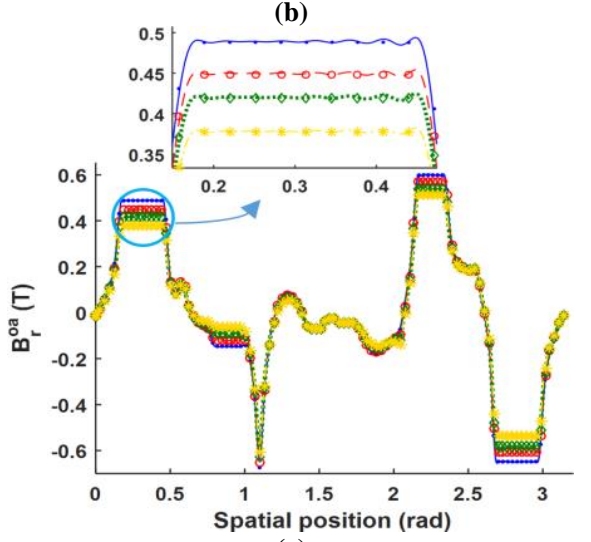

(c)

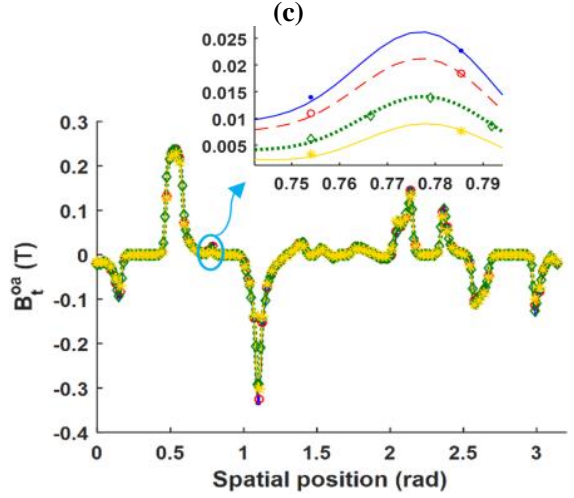

(d)

Analytic

- - - Two-seg. Halbach

Paralle

Radial

Fig. 9. The components of the magnetic flux density for the first case study, for different magnetization patterns in the inner and outer air-gaps due to both PMs and armature reaction. (a) Radial and (b) tangential components in the middle of inner air-gap. (c) Radial and (d) tangential components in the middle of outer air-gap.

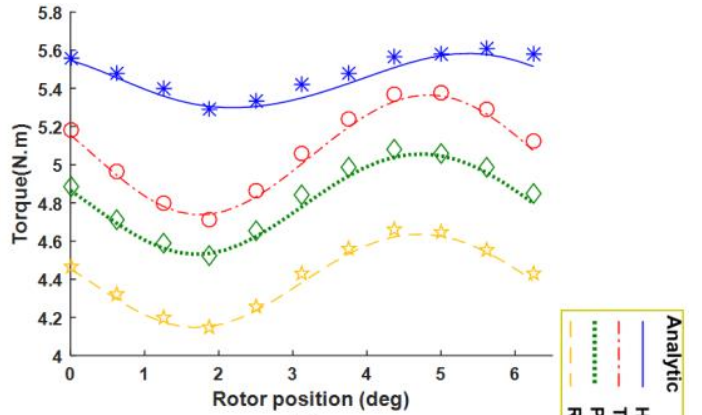

(a)

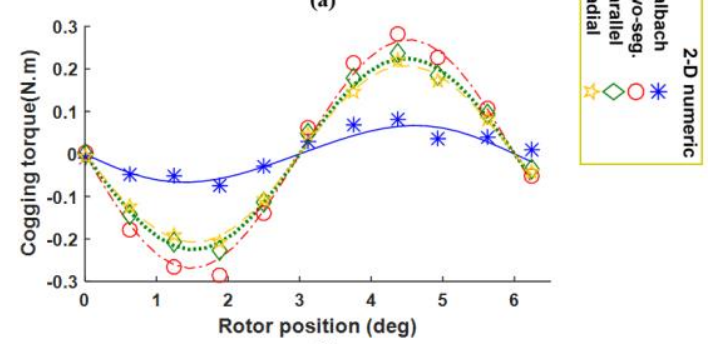

(b)

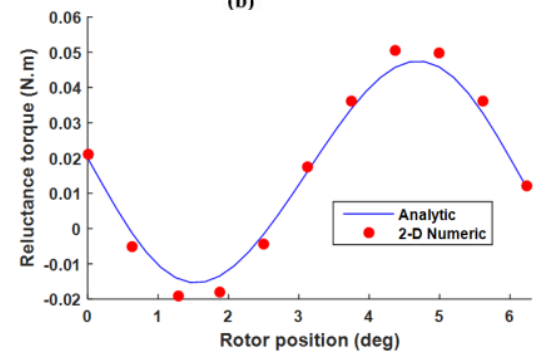

(c)

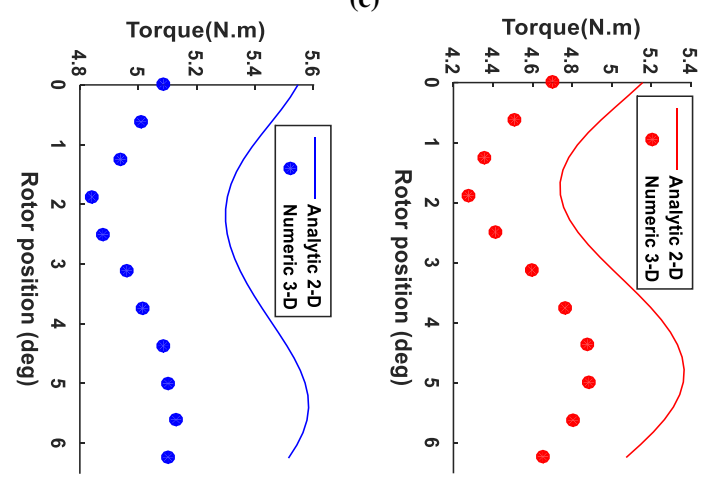

(d)

Torque(N.m)

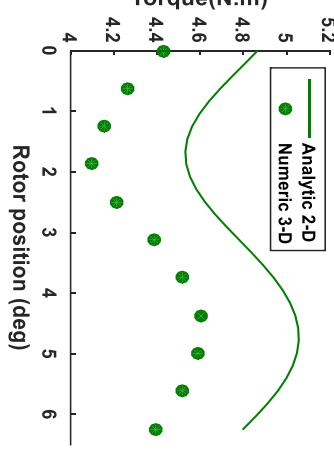

(f) (e)

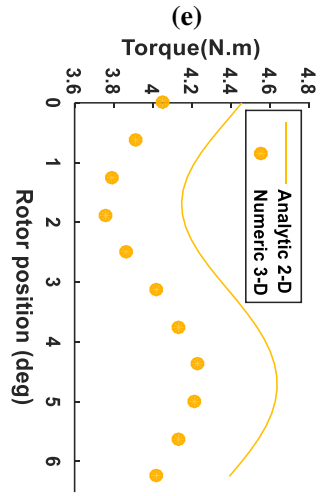

(g)
Fig. 10. (a) instantaneous torque (b) cogging torque (c) reluctance torque 3-D numeric vs. analytic for (d)Halbach magnetization pattern (e)Halbach 2seg. magnetization pattern (f)Parallel magnetization pattern (g)Radial magnetization pattern for the first case study. 


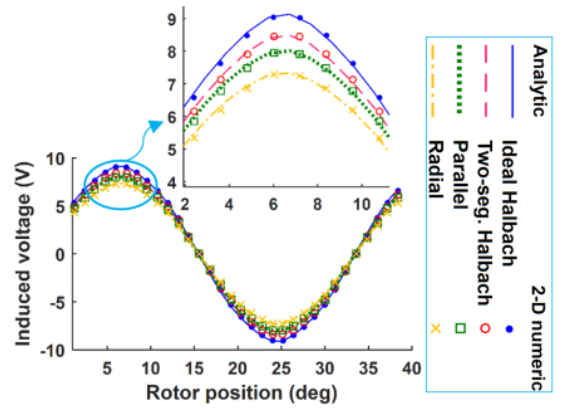

(a)

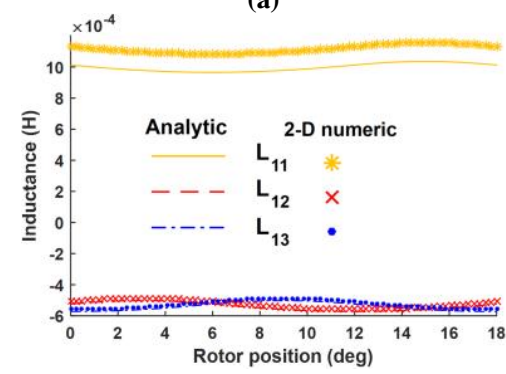

(b)

Fig. 11. (a) EMF (b) Inductances for the first case study.

\section{RESULTS OF THE SECOND CASE STUDY}

The parameters of the second case study have been listed in Table V. It is tried to choose different parameters than the first model and cause more saturation to verify the performance of the presented model. The results of the analytical model are compared to those of FEM. The winding configuration of the second case study is shown in Fig. 14 which creates 4 pole-pairs $\left(P_{s}\right)$.

\begin{tabular}{|c|c|c|}
\hline Parameters & Sym. & values \\
\hline Inner radius of PMs & $R_{i m}$ & $21.75 \mathrm{~mm}$ \\
\hline Inner radius of inner air-gap & $R_{\text {ia }}$ & $25.75 \mathrm{~mm}$ \\
\hline Inner radius of rotor & $R_{i r}$ & $26.25 \mathrm{~mm}$ \\
\hline Inner radius of outer air-gap & $R_{o a}$ & $30 \mathrm{~mm}$ \\
\hline Inner radius of slot-opening & $R_{s o}$ & $30.5 \mathrm{~mm}$ \\
\hline Inner radius of stator slots & $R_{\text {is }}$ & $31.75 \mathrm{~mm}$ \\
\hline Outer radius of stator slots & $R_{o s}$ & $42 \mathrm{~mm}$ \\
\hline Axial length of motor & $L$ & $25 \mathrm{~mm}$ \\
\hline Remenance of PMs & $B_{r}$ & $1.2 \mathrm{~T}$ \\
\hline Number of inner stator pole-pairs & $P_{i}$ & 9 \\
\hline Number of rotor pole-pieces & $N_{r}$ & 13 \\
\hline Number of stator slots & $N_{s}$ & 18 \\
\hline Number of stator pole-pairs & $P_{s}$ & 4 \\
\hline Rotor mechanical speed & $\omega_{r}$ & 400rpm \\
\hline Maximum value of the current & $i_{m}$ & $10.994 \mathrm{~A}$ \\
\hline Armature winding frequency & $f$ & $86.667 \mathrm{~Hz}$ \\
\hline Initial shifting for the armature winding & $\phi_{0}$ & $-40^{\circ}$ \\
\hline Number of turns per coil & $N_{t}$ & 12 \\
\hline Rotor slot span angle to rotor slot pitch & $\beta^{\prime}$ & 0.3 \\
\hline Stator slot span angle to stator slot pitch & $\delta^{\prime}$ & 0.8 \\
\hline $\begin{array}{l}\text { Stator slot-opening span angle to stator slot } \\
\text { nitnh }\end{array}$ & $\sigma^{\prime}$ & 0.55 \\
\hline Permeability of the slots & $\mu_{r}^{s_{j}}$ & 1 \\
\hline Filling factor of the slot & $F F$ & 0.5 \\
\hline $\begin{array}{l}\text { Maximum number of harmonics used in sub- } \\
\text { regions }\end{array}$ & $\begin{array}{l}N, K \\
U, V\end{array}$ & 150 \\
\hline
\end{tabular}

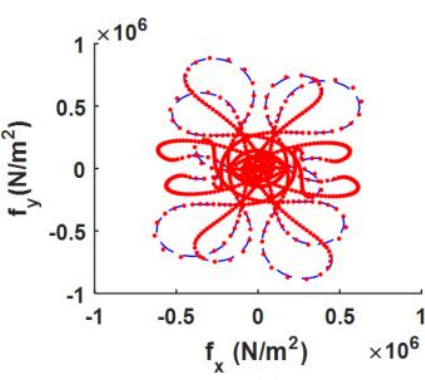

(a)

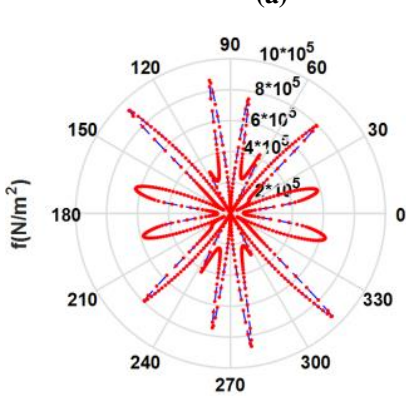

Spatial position (deg)

(c)
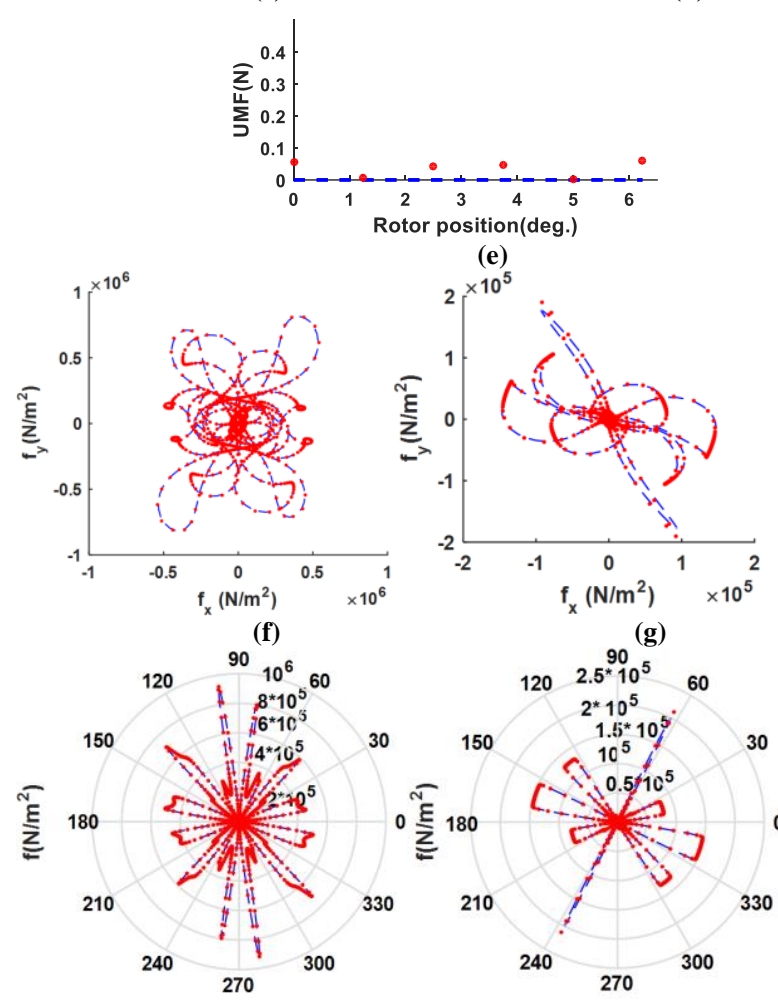

Spatial position (deg)

(h)

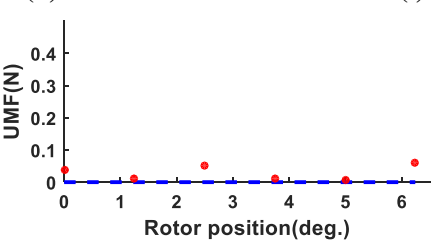

(j)

\section{Analytic - - - 2-D numeric $\bullet$}

Fig. 12. (a), (b) local tractions exerted respectively to the inner and outer surfaces of the rotor; (c), (d) their modulus; and (e) UMF due to the Ideal Halbach magnetization for the first case study.

(f), (g) local tractions exerted respectively to inner and outer surfaces of the rotor; (h), (i) their modulus; and (j) UMF due to the two-seg. Halbach magnetization for the first case study. 

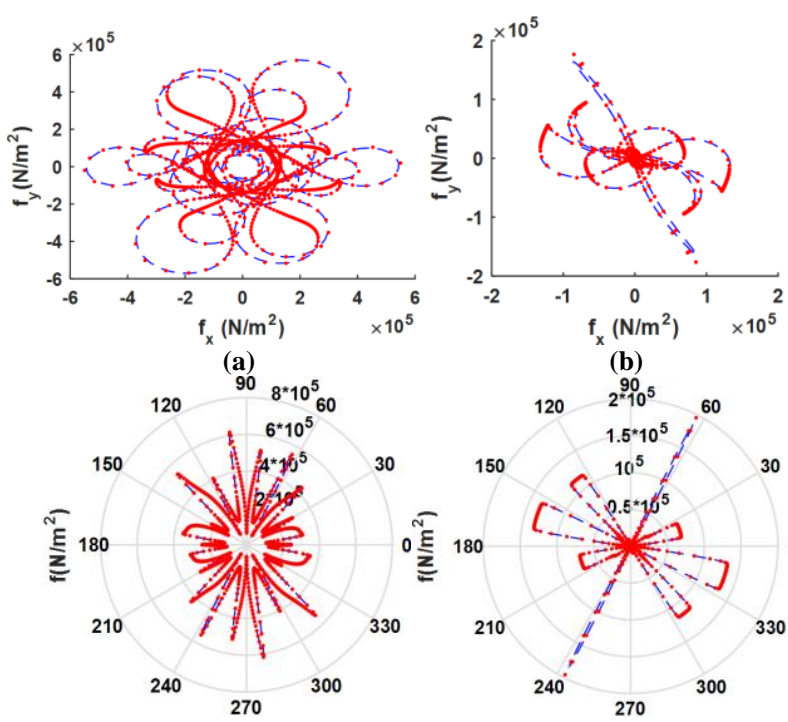

Spatial position (deg)

(c)

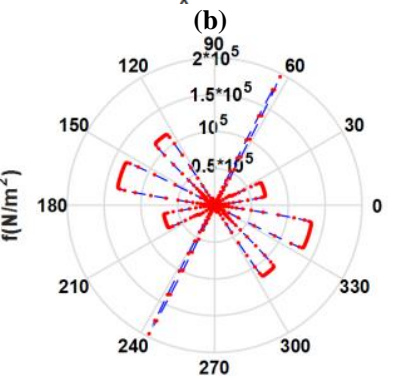

Spatial position (deg)

(d)

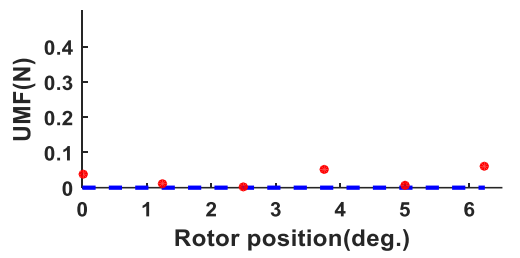

(e)
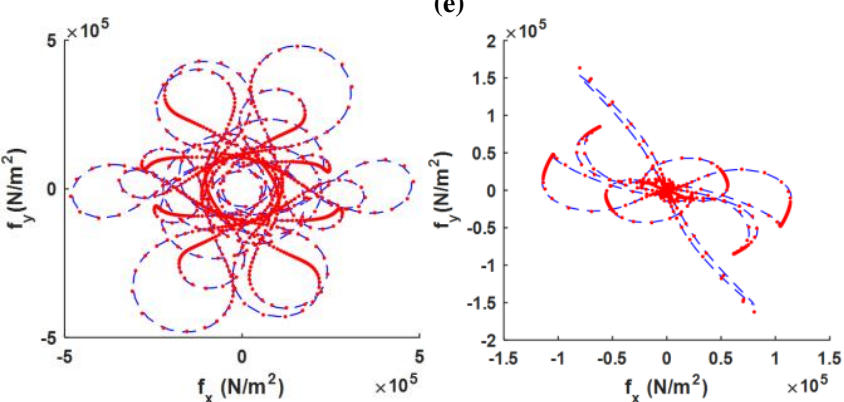

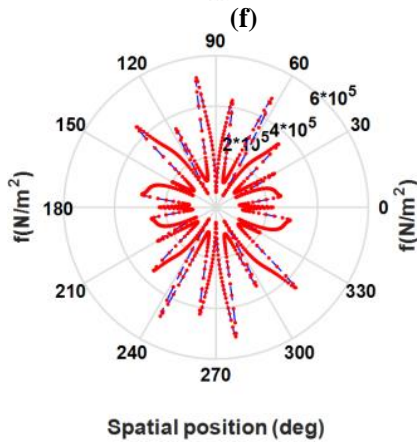

(h) (g)

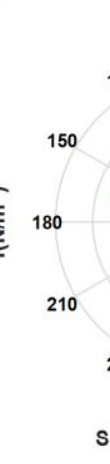

Spatial positi

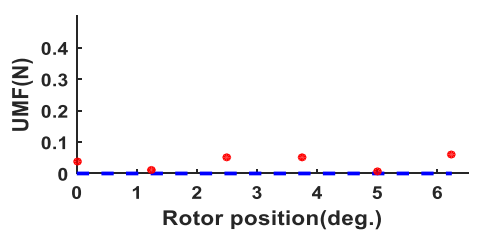

(j)

\section{Analytic - - 2-D numeric}

Fig. 13. (a), (b) local tractions exerted respectively to the inner and outer surfaces of the rotor; (c), (d) their modulus; and (e) UMF due to the parallel magnetization for the first case study.

(f), (g) local tractions exerted respectively to inner and outer surfaces of the rotor; (h), (i) their modulus; and (j) UMF due to the radial magnetization for the first case study.

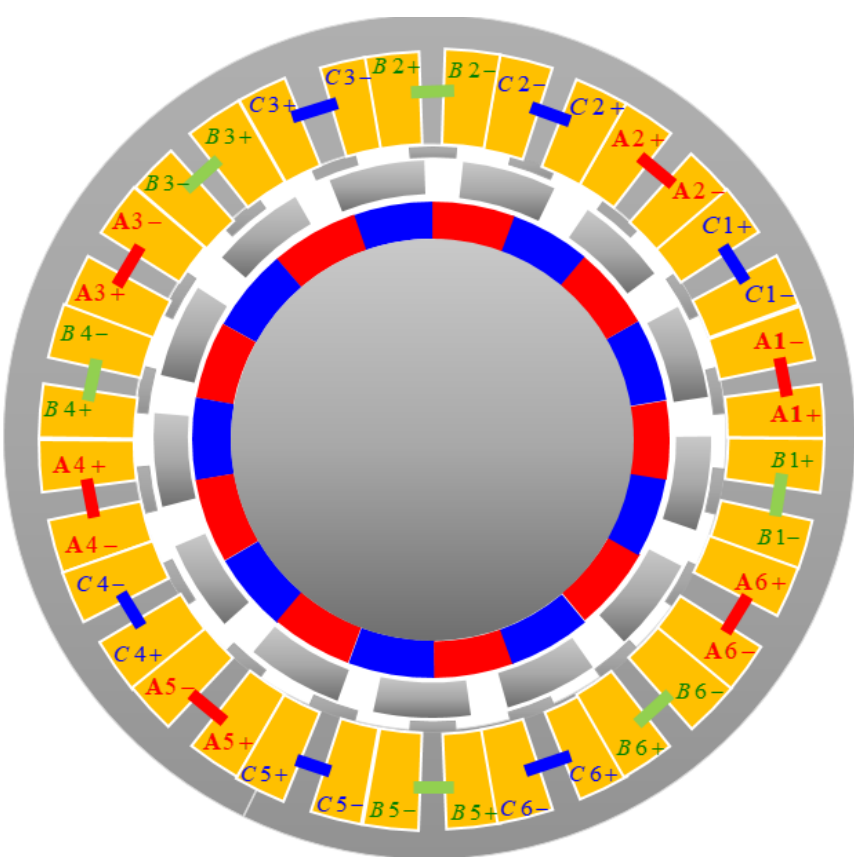

Fig. 14. Geometry of the second case study with non-overlapping winding

\section{A. Air-gap magnetic flux density}

Figs. 15 (a)-(d) show the radial and tangential components of the magnetic flux density due to both open circuit and armature reaction for the presented magnetization patterns, in the middle of the inner and outer air-gap sub-domains. The initial rotor position is set to zero and current density of the phases are set to $J_{A}=-3.2139 \mathrm{~A} / \mathrm{mm}^{2} \quad, \quad J_{B}=-1.7101 \mathrm{~A} / \mathrm{mm}^{2} \quad$ and $J_{C}=4.924 \mathrm{~A} / \mathrm{mm}^{2}$. As clear from the figures, the flux density distributions have conformity with the numerical results for different magnetization patterns.

\section{B. Torque}

The total instantaneous torque of the second case study, for the four presented magnetization patterns have been shown in Fig. 16 (a). As it is expected, the ideal Halbach magnetization pattern has the best result on the output torque and has 30.4\% higher output torque in comparison with the radial magnetization pattern. Also the two-segment Halbach and parallel magnetization pattern of the PMs respectively develop $20.053 \%$ and $7.2 \%$ higher output torque in comparison with the radial magnetization pattern. It is worth mentioning that the cogging and reluctance torques of this case study are miniscule.

The result of the 3-D linear FEM for the magnetization patterns compared with the proposed analytical method as shown in Fig. 16 (b)-(e). The relative error between the proposed 2-D analytical model and 3-D FEM model is about 9.1\% for ideal Halbach, $10.05 \%$ for two-segment Halbach, $10.16 \%$ for parallel and $10.83 \%$ for radial magnetization pattern. These discrepancies may have two reasons. One is due to the 3-D FEM mesh size and the second one is neglecting the end effect in the 2-D analytic model.

\section{EMF and inductances}

The EMF of the first phase for the presented magnetization patterns has been depicted in Fig. 17. The ideal Halbach magnetization pattern outperforms the others in terms of EMF. The peak value of the induced voltage for ideal Halbach is 2.964 
$\mathrm{V}$ which is $30 \%$ more than of the radial magnetization pattern EMF. The peak value of EMF for the two-segment Halbach is $2.719 \mathrm{~V}$ and for the parallel magnetization pattern is $2.395 \mathrm{~V}$.

The self-inductance of the first phase and the mutualinductances between the first phase and the other two phases have been depicted in Fig. 18. The analytic and 2-D numeric results show good agreement in mutual inductances. The selfinductance of two method have little discrepancy which may refer to the difference of the inductance calculation methods in the analytic and FEM model.

\section{UMF and local tractions}

The analytic results of the unbalanced magnetic force for the different magnetization patterns are compared to those obtained from the FEM as shown in Fig.19. As evident from the results, the values of the UMF for the second case study is greater than those of the first case study. It is due to different winding configuration and pole combination.

The local traction and its modulus exerted on the inner and outer surface of the rotor, for the four magnetization patterns are respectively presented in Figs. 20-23 (a)-(d). The figures show the distribution of the modulus local tractions is diagonally asymmetric which results in a higher UMF compared to the first case study.

\section{DISCUSSION}

\section{A. Saturation phenomenon}

The average of the instantaneous torque versus the maximum values of the armature current density, for the first case study is shown in Fig. 24 (a) to investigate the saturation effect on the accuracy of the proposed analytical model. In this figure, the results of the proposed analytical model are compared with those of FEM considering the nonlinear behavior of the iron. Figs. 24 (b) and (c), show the magnitude of the flux density in different parts of the model, obtained by the numerical method. In Fig. 24 (b), the maximum value of the current density is $5 \mathrm{~A} / \mathrm{mm}^{2}$ in which the system is almost unsaturated. In Fig. 24 (c), the maximum value of the current density is $15 \mathrm{~A} / \mathrm{mm}^{2}$ in which the system is partially saturated. Fig. 24 (a) clearly shows that the proposed analytical model remains accurate for large values of the armature current density, as the discrepancy between the analytic and numeric methods for the instantaneous torque, when $J_{\max }=5 \mathrm{~A} / \mathrm{mm}^{2}$, is about $3 \%$. With increasing the current density, the discrepancy increases and reaches $9.9 \%$ for $J_{\max }=15 \mathrm{~A} / \mathrm{mm}^{2}$.

Also the saturation phenomenon of the second case study has been investigated in Fig. 25. The average torque versus maximum current density of the phases has been depicted in Fig. 25 (a). It is evident from Fig. 25 (a), the discrepancy between the analytic and numeric method is less than $4.7 \%$ for maximum current density equal to $5 \mathrm{~A} / \mathrm{mm}^{2}$. Also by increasing the current density, discrepancy between the analytic and 2-D non-linear numeric methods increases and the maximum difference, which is $18.6 \%$, occurs at $J_{\text {max }}=15 \mathrm{~A} / \mathrm{mm}^{2}$.

It is noteworthy that the maximum size of meshes in the 2-D numeric method is $0.1 \mathrm{~mm}$.
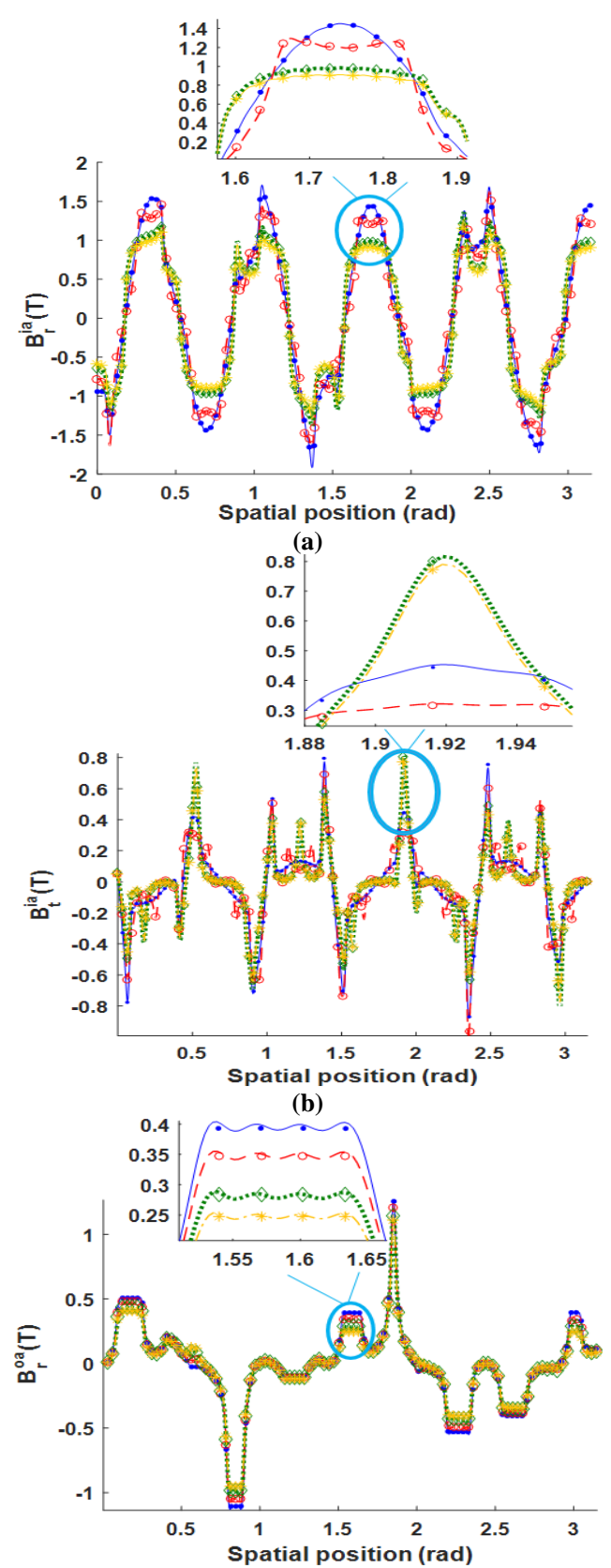

(c)

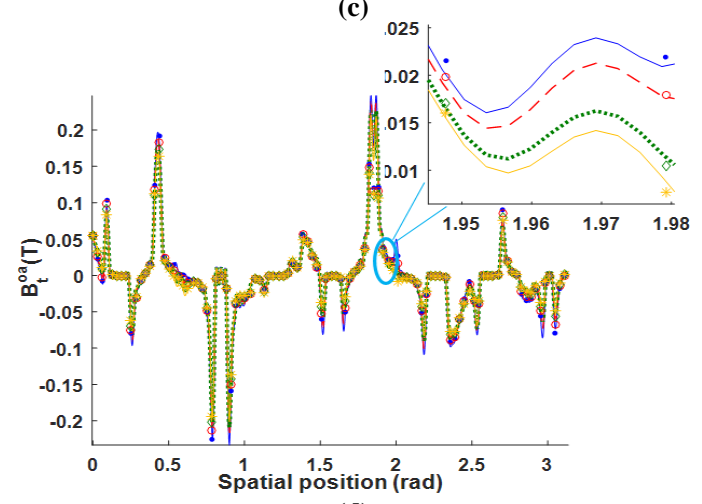

(d)

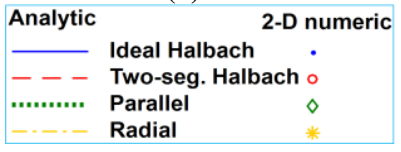

Fig. 15. The components of the magnetic flux density, for different magnetization patterns in the inner and outer air-gaps due to both PMs and armature reaction for the second case study.

(a) Radial and (b) tangential components in the middle of inner air-gap. (c) Radial and (d) tangential components in the middle of outer air-gap. 


\section{B. Effect of the rotor slot ratio}

To investigate the influence of the rotor slot ratio, $\beta^{\prime}$ as expressed in (6), on the average of the instantaneous torque and torque ripple, this value is changed for different magnetization patterns and the results have been shown in Fig. 26 (a)-(d) for the first case study. According to these results, the best rotor slot ratio which results in the maximum average torque for all presented magnetization patterns is 0.3 , while the minimum value of the torque ripple occurs when $\beta^{\prime}=0.6$.

\section{Effect of the stator slot-opening ratio}

The effect of the stator slot-opening ratio, $\sigma^{\prime}$, on the average torque and torque ripple is shown in Fig. 27 for different magnetization patterns on the first case study. It is evident that the slot-opening ratio of 0.4 , not only enhances the average torque, but also, decreases the torque ripple.

\section{Effect of the segment ratio in two-segment Halbach magnetization pattern}

In the two-segment Halbach magnetization pattern, there is a flexibility to change the ratio of the width of segments to enhance the performance of the machine. Fig. 28 shows the average torque and torque ripple versus the ratio of the middle part of the two-segment Halbach PM for the first case study. According to the results, the segment ratio of 0.8 (middle part equal to 0.8 and each side part equal to 0.1 ), simultaneously maximizes the average torque and minimizes the torque ripple.

\section{E. Execution time}

The computation for the 2-D analytical model, 2-D and 3-D FEM for the first case study, carried out by a computer with CPU i7 4GHz, 32 GB of RAM. The execution time has been calculated for just one rotor position. It is noteworthy that the number of harmonics in all sub-domains is selected according to Table IV. Also the minimum lengths of mesh elements in 2$\mathrm{D}$ and 3-D numeric methods are respectively set to $0.1 \mathrm{~mm}$ and $3 \mathrm{~mm}$.

The execution times are tabulated in Table VI. It is clear that the analytical model is 14 times faster than 2-D FEM and 94.15 times faster than 3-D FEM.

TABLE VI

EXECUTION TIME OF USED METHODS

\begin{tabular}{|l|c|c|c|}
\hline Methods & 2-D analytic & 2-D numeric & 3-D numeric \\
\hline Execution time & $20 \mathrm{~s}$ & $280 \mathrm{~s}$ & $1883 \mathrm{~s}$ \\
\hline
\end{tabular}

\section{F. Pros and cons}

From the view point of computational speed, the proposed 2$\mathrm{D}$ analytical model is among the best options for preliminary optimization problems, where thousands of iterations are required.

Although the proposed model has limitation to incorporate the saturation effect, it is possible to indirectly calculate the magnetic flux of the non-active subdomains (ferromagnetic parts), similar to the EMF calculation procedure, and approximately check the level of saturation in various parts of the machine using the proposed 2-D analytical model.
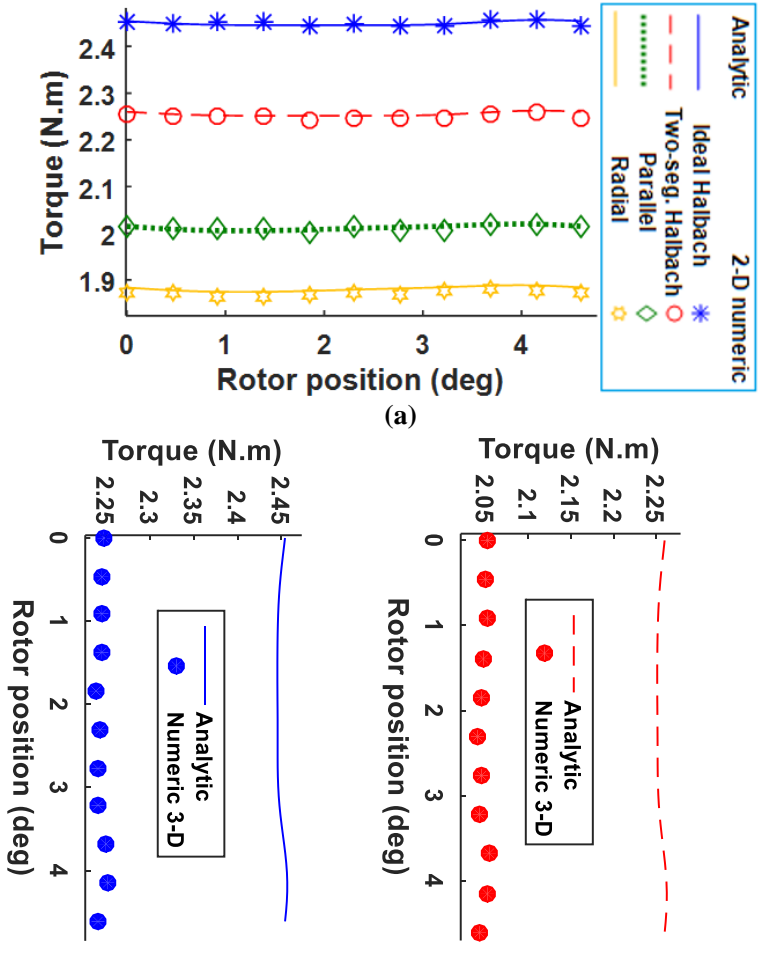

(a)

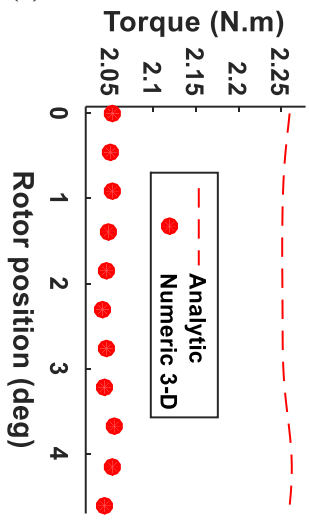

(b)

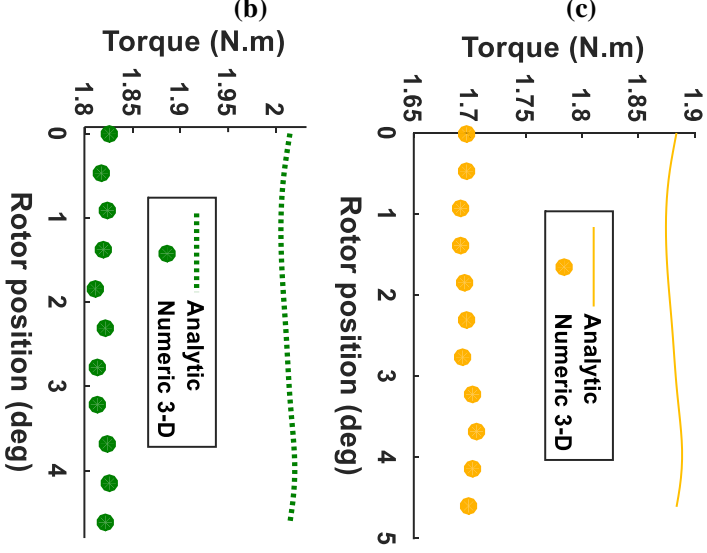

(d)

Fig. 16. instantaneous torque (a) for different magnetization patterns. Comparison of 2-D analytic and 3-D FEM for (b) ideal Halbach (c) two-seg. Halbach (d) Parallel and (e) Radial magnetization patterns for the second case stydy.

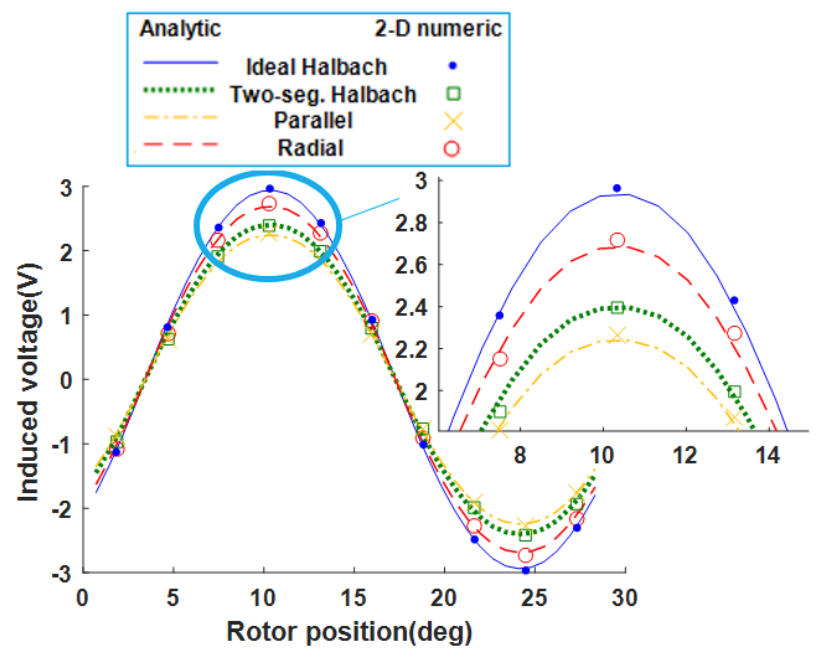

Fig. 17. EMF of the second case study for different magnetization patterns. 


\section{CONCLUSION}

In this paper, a 2-D analytical magnetic model is presented for flux-reversal partitioned stator machines with four types of the magnetization patterns having inner surface mounted PMs. The magnetic flux density distribution is analytically computed in active sub-domains, which consist of the PM inner stator, inner and outer air-gaps, rotor slots, stator slots and stator slotopenings. Based on the computed magnetic flux density, the crucial quantities of the machine such as the mutual torque, cogging torque, unbalanced magnetic force, EMF, and inductances are calculated while different magnetization patterns are considered. Results of the analytical model have been compared to those obtained from 2-D and 3-D FEM. The analytical and 2-D numerical results have good conformity for the presented case studies. The machine with the ideal Halbach and two-segment Halbach magnetization patterns enhances the instantaneous torque and decreases the torque ripple, compared to those with the radial and parallel magnetization patterns. To show the saturation phenomena, the model under different load conditions has been investigated and the results indicate the model has acceptable accuracy even when the system is partially saturated. Also, the investigation of some parameters such as the rotor slot ratio, stator slot-opening ratio, the segment ratio of the two-segment magnetization pattern on the instantaneous torque and torque ripple shows that the design parameters can be adjusted to increase the instantaneous torque, while decreasing the cogging torque. Finally, the execution times, advantages and disadvantages of the presented analytical model have been compared with the numerical models.

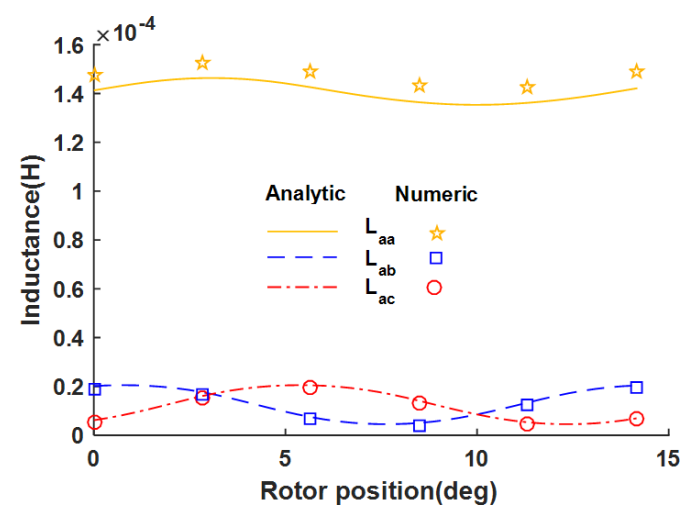

Fig. 18. Self and mutual inductances of the second case study.

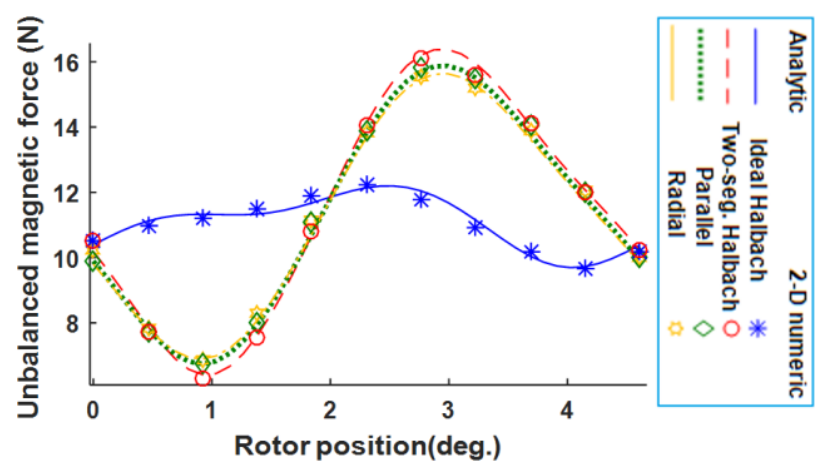

Fig. 19. UMF of the second case study due to the different magnetization patterns.

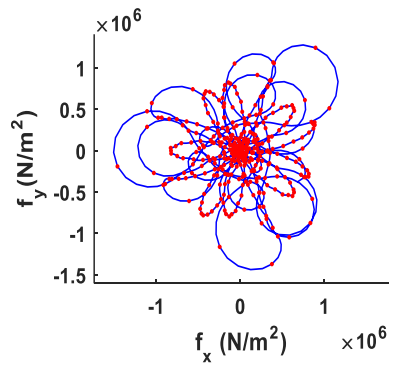

(a)

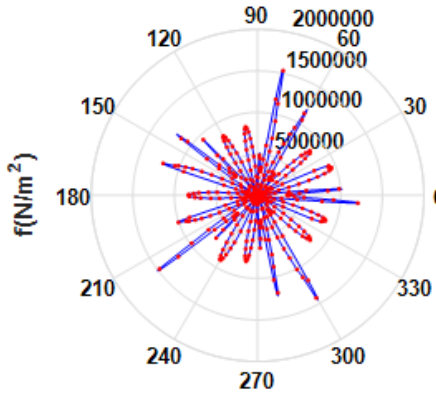

Spatial position (deg)

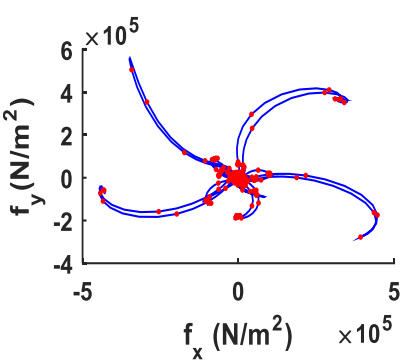

(b)

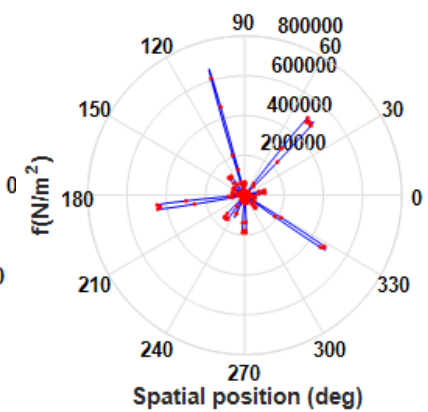

Analytic

2-D numeric .

Fig. 20. (a), (b) local tractions exerted respectively to the inner and outer surfaces of the rotor for the second case study; (c), (d) their modulus for the Ideal Halbach magnetization pattern.

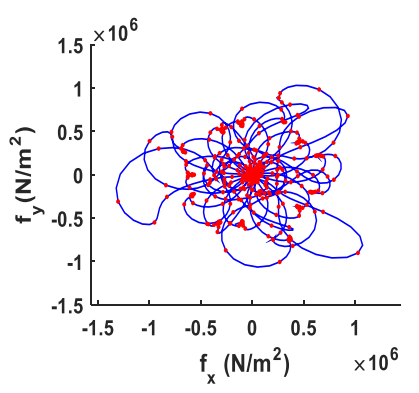

(a)

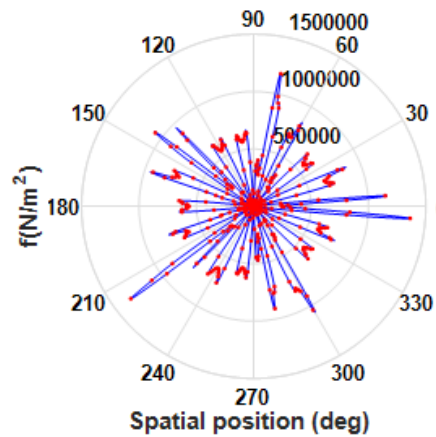

(c)

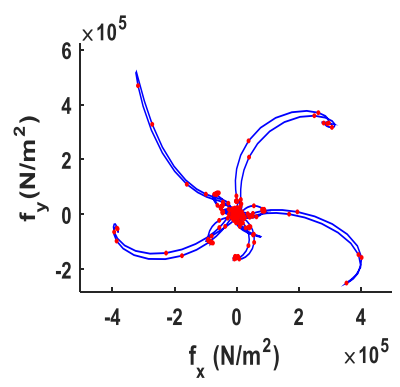

(b)

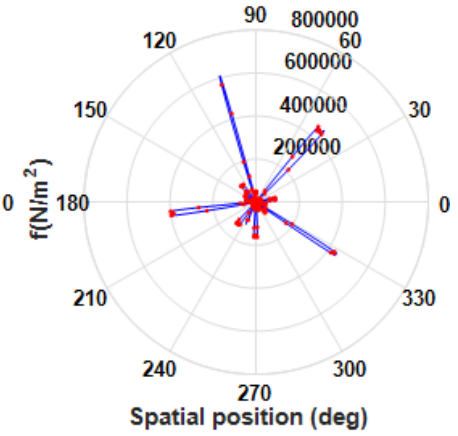

(d)

$$
\text { Analytic } \quad \text { 2-D numeric . }
$$

Fig. 21. (a), (b) local tractions exerted respectively to the inner and outer surfaces of the rotor for the second case study; (c), (d) their modulus for the twosegment Halbach magnetization pattern. 


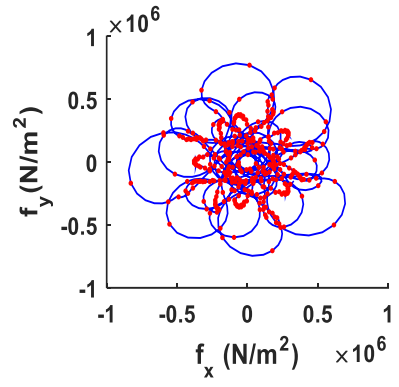

(a)

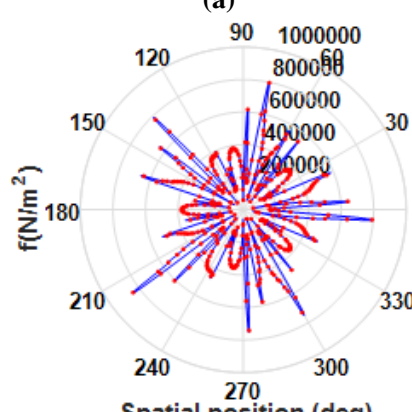

Spatial position (deg)

(c)

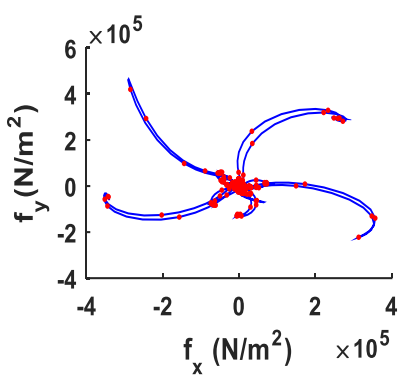

(b)

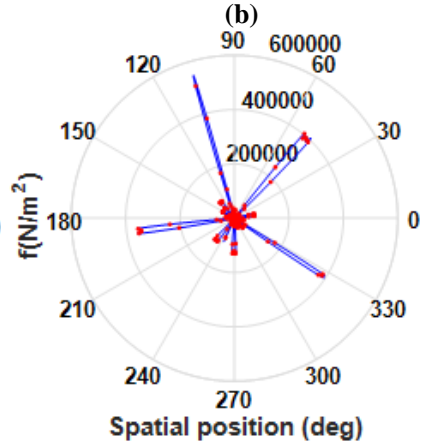

(d)

$$
\text { Analytic 2-D numeric . }
$$

Fig. 22. (a), (b) local tractions exerted respectively to the inner and outer surfaces of the rotor for the second case study; (c), (d) their modulus for the parallel magnetization pattern.

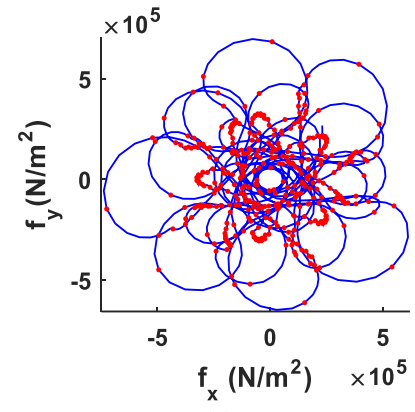

(a)

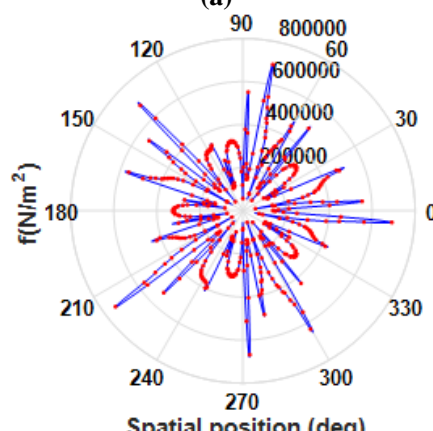

Spatial position (deg)

(c)

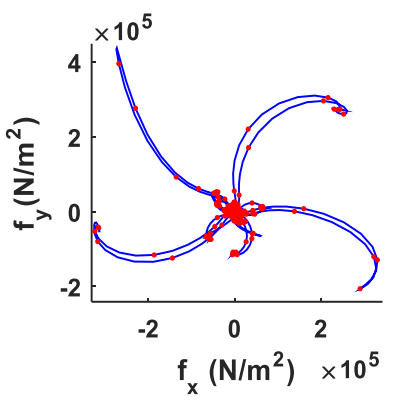

(b)

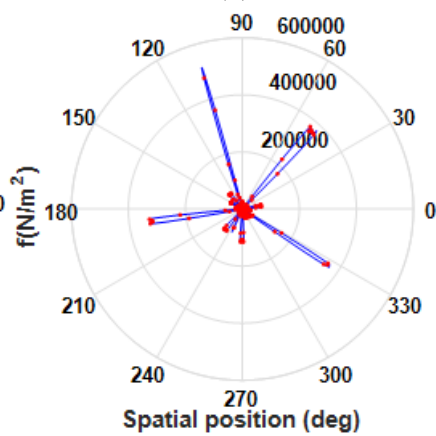

(d)
Analytic 2-D numeric .

Fig. 23. (a), (b) local tractions exerted respectively to the inner and outer surfaces of the rotor for the second case study; (c), (d) their modulus for the radial magnetization pattern.

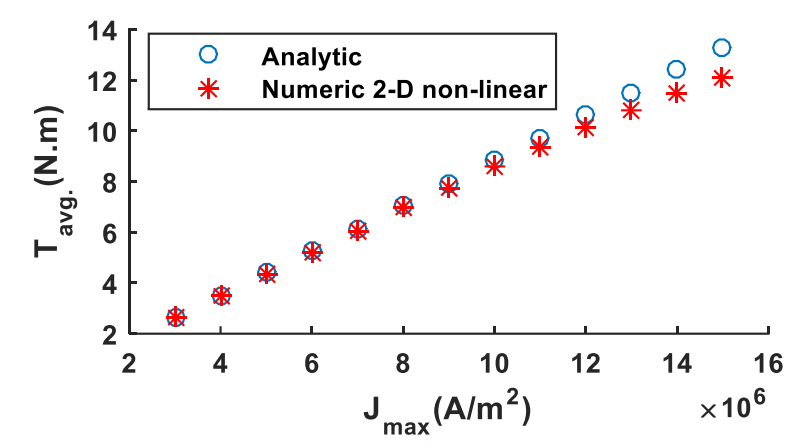

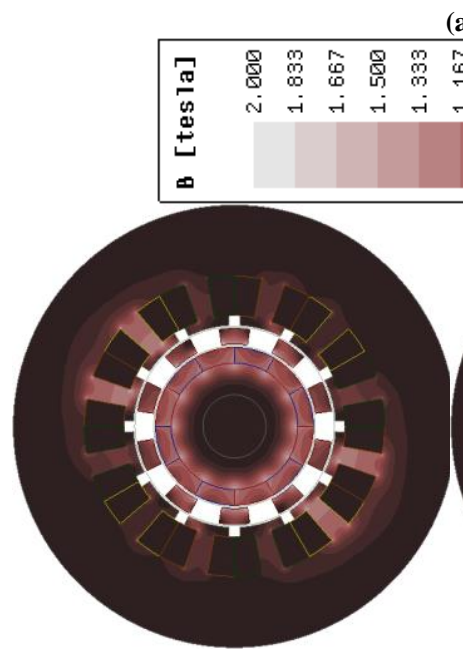

(b) (a)

Fig. 24. (a) instantaneous torque vs. maximum value of current density with the radial magnetization pattern (b) magnitude of the flux density for $J_{\max }=5 \mathrm{~A} / \mathrm{mm} 2$ \& (c) for $J_{\max }=15 \mathrm{~A} / \mathrm{mm} 2$.

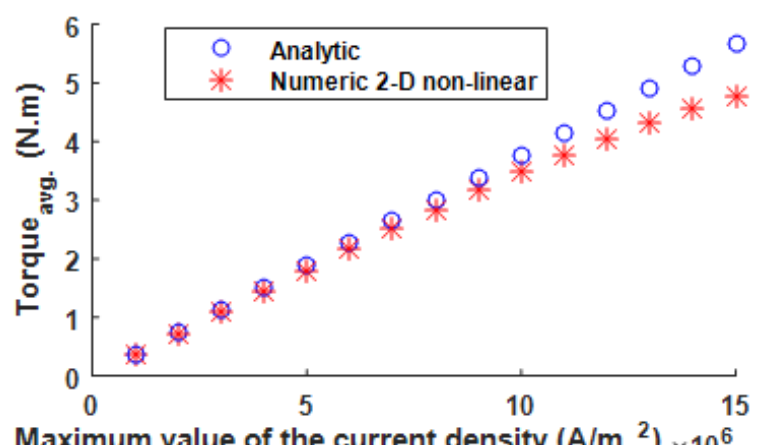

Maximum value of the current density $\left(\mathrm{A} / \mathrm{m}^{2}\right) \times 10^{6}$

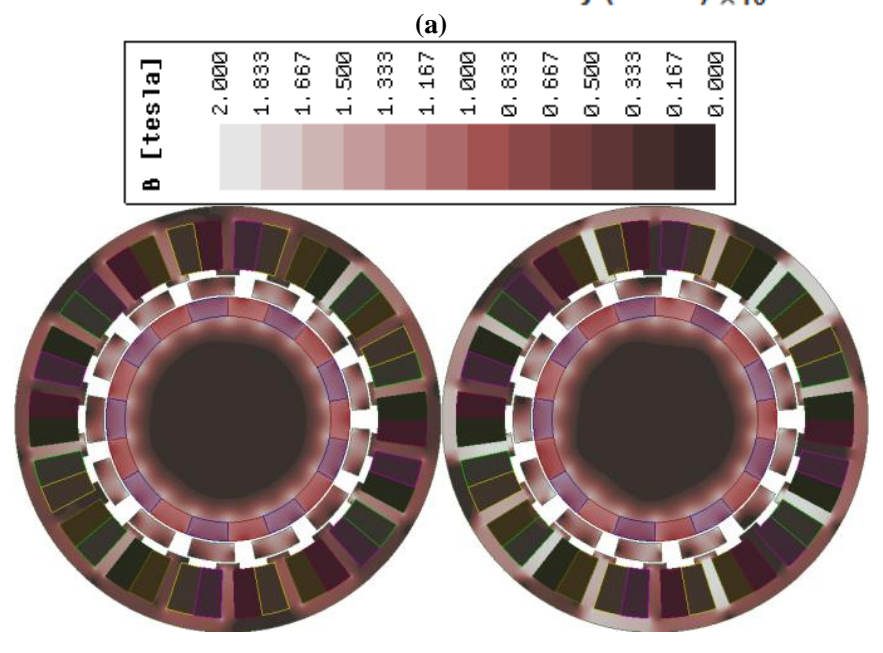

(b)

(c)

Fig. 25. (a) instantaneous torque vs. maximum value of current density with the radial magnetization pattern (b) magnitude of the flux density for $J_{\max }=5$ $\mathrm{A} / \mathrm{mm} 2 \&$ (c) for $J_{r m s}=15 \mathrm{~A} / \mathrm{mm} 2$ with the radial magnetization pattern. 


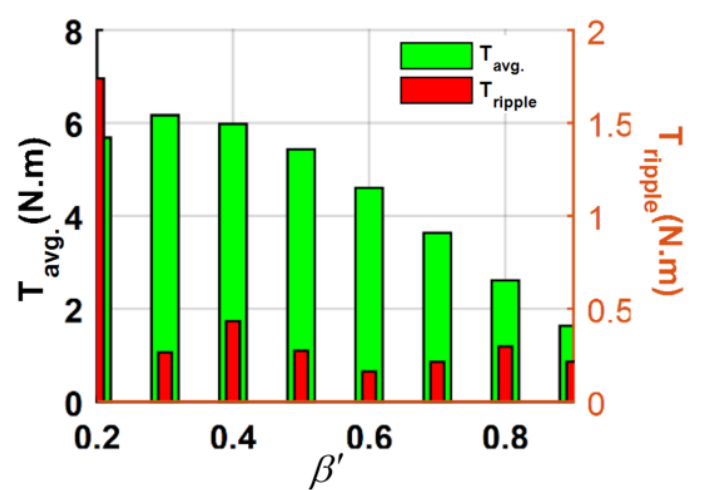

(a)

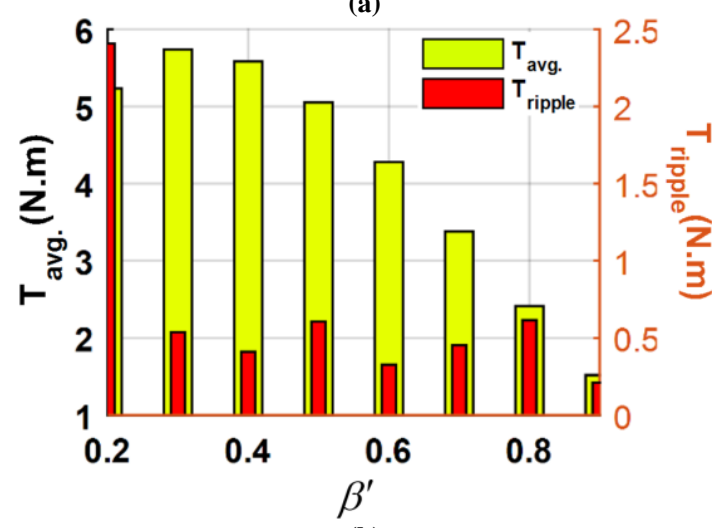

(b)

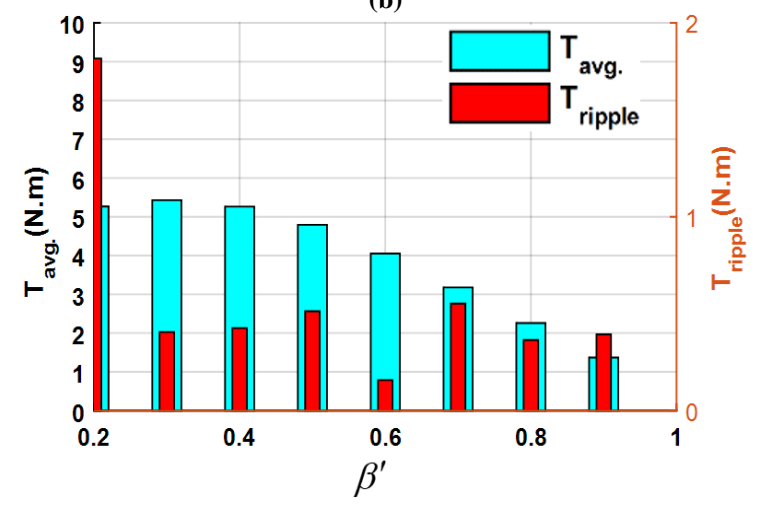

(c)

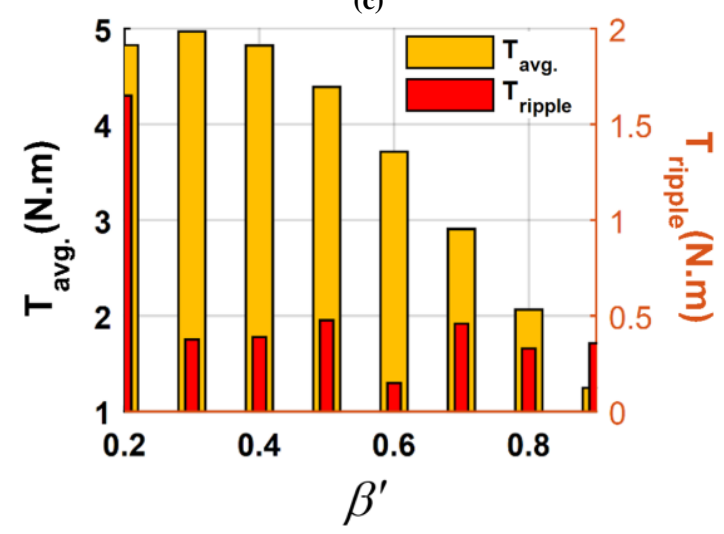

(d)

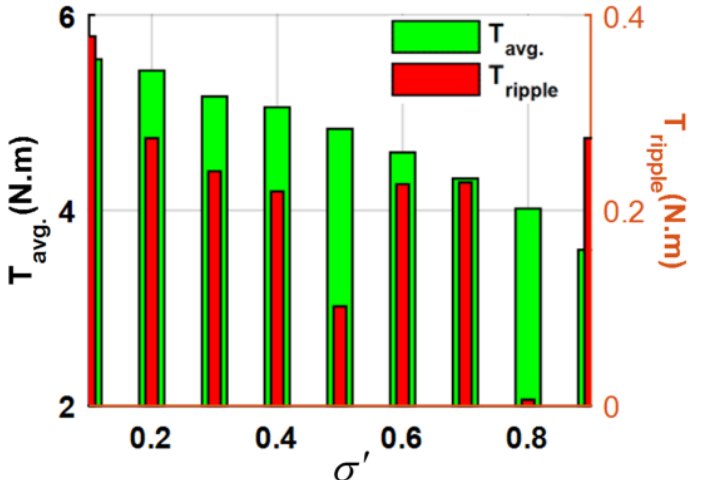

(a)

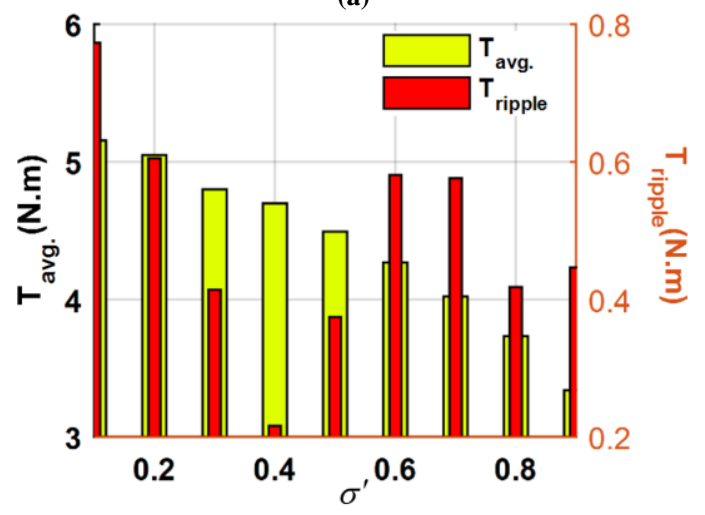

(b)

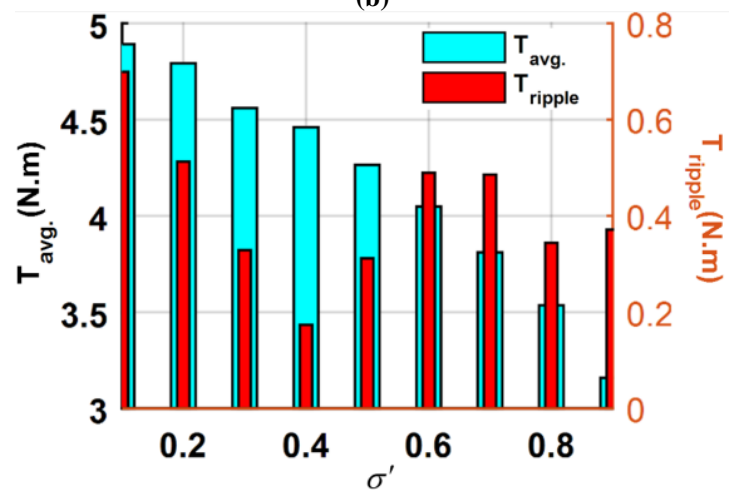

(c)

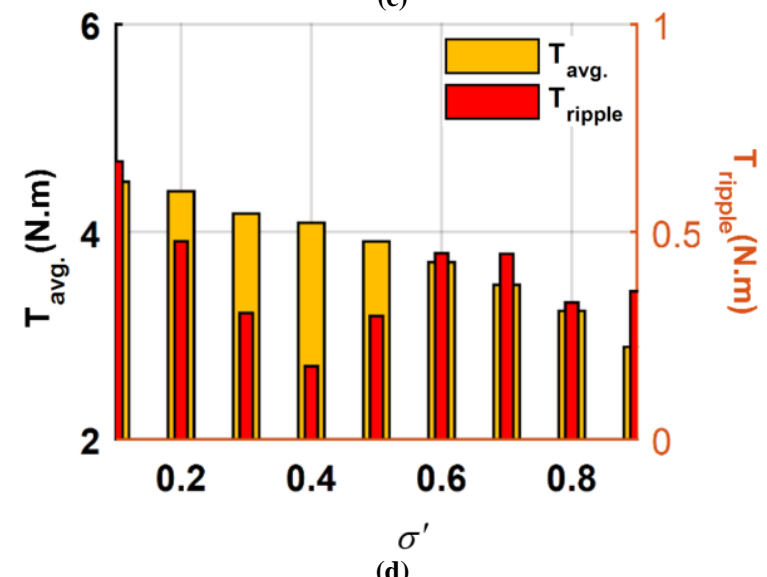

(d)

Fig. 26. Effect of the rotor slot ratio on the average torque and torque ripple in the Fig. 27. Effect of the stator slot-opening ratio on the average torque and Fig. 26. Effect of the rotor slot ratio on the average torque and torque ripple in the
first case study for (a) Ideal Halbach (b) Two-segment (c) Parallel (d) Radial 


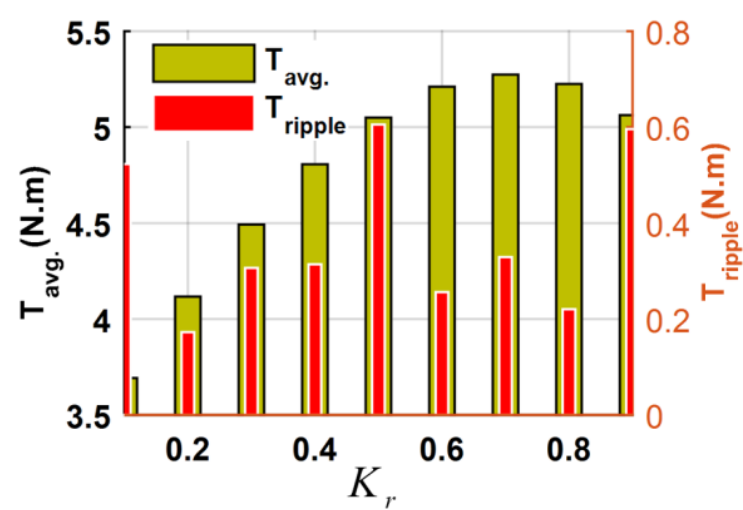

Fig. 28. Changing the ratio of segments in the two-segment magnetization pattern in the first case study.

\section{REFERENCES}

[1] Z. Q. Zhu and J. T. Chen, "Advanced Flux-Switching Permanent Magnet Brushless Machines," IEEE Transactions on Magnetics, vol. 46, no. 6, pp. 1447-1453, June 2010.

[2] M. Cheng, W. Hua, J. Zhang and W. Zhao, "Overview of StatorPermanent Magnet Brushless Machines," IEEE Transactions on Industrial Electronics, vol. 58, no. 11, pp. 5087-5101, Nov. 2011.

[3] K. Atallah and D. Howe, "A novel high-performance magnetic gear," IEEE Transactions on Magnetics, vol. 37, no. 4, pp. 2844-2846, July 2001.

[4] A. Rahideh, A. A. Vahaj, M. Mardaneh and T. Lubin, "Twodimensional analytical investigation of the parameters and the effects of magnetisation patterns on the performance of coaxial magnetic gears," IET Electrical Systems in Transportation, vol. 7, no. 3, pp. 230-245, 92017.

[5] T. Lubin, S. Mezani, A. Rezzoug, "Analytical computation of the magnetic field distribution in a magnetic gear," IEEE Transactions on Magnetics, vol. 46, no. 7, pp. 2611-2621, Jul. 2010.

[6] D. J. Evans and Z. Q. Zhu, "Novel Partitioned Stator Switched Flux Permanent Magnet Machines," IEEE Transactions on Magnetics, vol. 51, no. 1, pp. 1-14, Jan. 2015, Art no. 8100114.

[7] Z. Q. Zhu, "Overview of novel magnetically geared machines with partitioned stators" IET Electric Power Applications, Volume 12, Issue 5, May 2018, p. $595-604$

[8] T. H. Kim and J. Lee, "A study of the design for the flux reversal machine," IEEE Transactions on Magnetics, vol. 40, no. 4, pp. 20532055, Jul. 2004.

[9] J. T. Chen, Z. Q. Zhu, S. Iwasaki, and R. P. Deodhar, "Influence of slot opening on optimal stator and rotor pole combination and electromagnetic performance of switched-flux PM brushless AC machines," IEEE Transactions on Industry Applications, vol. 47, no. 4, pp. 1681-1691, Jul./Aug. 2011.

[10] M. Cheng, K. T. Chau, and C. C. Chan, "Design and analysis of a new doubly salient permanent magnet motor," in IEEE Transactions on Magnetics, vol. 37, no. 4, pp. 3012-3020, July 2001.

[11] Z. Z. Wu, and Z. Q. Zhu, "Analysis of Magnetic Gearing Effect in Partitioned Analysis of Magnetic Gearing Effect in Partitioned stator switched flux machine" IEEE Transactions on Energy Conversion, vol. 31, no. 4, pp. 1239 - 1249, Dec. 2016.

[12] Z. Q. Zhu, Z. Z. Wu, D. J. Evans, and W. Q. Chu, "Novel Electrical Machines Having Separate PM Excitation Stator," IEEE Transactions on Magnetics, vol. 51, no. 4, pp. 1-9, April 2015, Art no. 8104109 .

[13] Z. Q. Zhu, H. Hua, D. Wu, J. T. Shi, and Z. Z. Wu, "Comparative Study of Partitioned Stator Machines with Different PM Excitation Stators," IEEE Transactions on Industry Applications, vol. 52, no. 1, pp. 199-208, Jan.-Feb. 2016.

[14] Z. Z. Wu, and Z. Q. Zhu, "Partitioned Stator Flux Reversal Machine with Consequent-Pole PM Stator," IEEE Transactions on Energy Conversion, vol. 30, no. 4, pp. 1472-1482, Dec. 2015.

[15] Z. Z. Wu, Z. Q. Zhu, and H. L. Zhan, "Comparative Analysis of Partitioned Stator Flux Reversal PM Machines Having FractionalSlot Nonoverlapping and Integer-Slot Overlapping Windings," in IEEE Transactions on Energy Conversion, vol. 31, no. 2, pp. 776788, June 2016.

[16] Z.Z. Wu, Z.Q. Zhu, and H.L. Zhan, 'Comparison of partitioned stator flux reversal PM machine and magnetically geared machine operating at stator-PM and rotor-PM modes', IEEE Transactions on Energy Conversion, 2017, 32, (3), pp. 903-917.

[17] J. T. Shi, A. M. Wang and Z. Q. Zhu, "Influence of PM- and Armature Winding-Stator Positions on Electromagnetic Performance of Novel Partitioned Stator Permanent Magnet Machines," in IEEE Transactions on Magnetics, vol. 53, no. 1, pp. 1-12, Jan. 2017, Art no. 8100212.

[18] M. Pourahmadi-Nakhli, A. Rahideh and M. Mardaneh, "Analytical 2D Model of Slotted Brushless Machines With Cubic Spoke-Type Permanent Magnets," in IEEE Transactions on Energy Conversion, vol. 33, no. 1, pp. 373-382, March 2018.

[19] X. X. Zhang, X. Liu, J. L. Liu, and Z. Chen, "Analytical investigation on the power factor of a flux-modulated permanent-magnet synchronous machine," IEEE Trans. Magn., vol. 51, no. 11, pp. 1-4, Nov. 2015.

[20] X. X. Zhang, X. Liu, and Z. Chen, "Investigation of unbalanced magnetic force in magnetic geared machine using analytical methods," IEEE Trans. Magn., vol. 52, no. 7, pp. 1-4, July 2016.

[21] Z. Djelloul-Khedda, K. Boughrara, F. Dubas, A. Kechroud, and A. Tikellaline, "Analytical Prediction of Iron-Core Losses in FluxModulated Permanent-Magnet Synchronous Machines," IEEE Transactions on Magnetics, vol. 55, no. 1, pp. 1-12, Jan. 2019, Art no. 6300112 .

[22] S. T. Boroujeni, and H. B. Naghneh, "Analytical modelling and prototyping a slotless surface-inset PM machine," IET Electric Power Applications, vol. 11, no. 3, pp. 312-322, 32017.

[23] S. G. Min and B. Sarlioglu, "Fast and Systematic Design Optimization of Surface-Mounted PM Machines Using Advanced Analytical Models and Subharmonic Elimination Methods," IEEE Transactions on Magnetics, vol. 55, no. 1, pp. 1-16, Jan. 2019, Art no. 8100216.

[24] K. Shin, H. Cho, K. Kim, K. Hong, and J. Choi, "Analytical Investigation of the On-Load Electromagnetic Performance of Magnetic-Geared Permanent-Magnet Machines," IEEE Transactions on Magnetics, vol. 54, no. 11, pp. 1-5, Nov. 2018, Art no. 8203905.

[25] L. Roubache, K. Boughrara, F. Dubas, and R. Ibtiouen, "New Subdomain Technique for Electromagnetic Performances Calculation in Radial-Flux Electrical Machines Considering Finite Soft-Magnetic Material Permeability," IEEE Transactions on Magnetics, vol. 54, no. 4, pp. 1-15, April 2018, Art no. 8103315.

[26] X. Yin, Y. Fang, X. Huang, and P. Pfister, "Analytical Modeling of a Novel Vernier Pseudo-Direct-Drive Permanent-Magnet Machine," IEEE Transactions on Magnetics, vol. 53, no. 6, pp. 1-4, June 2017, Art no. 7207404.

[27] S. Teymoori, A. Rahideh, H. Moayed-Jahromi, and M. Mardaneh, "2D Analytical Magnetic Field Prediction for Consequent-Pole Permanent Magnet Synchronous Machines," IEEE Transactions on Magnetics, vol. 52, no. 6, pp. 1-14, June 2016, Art no. 8202114.

[28] A. Dalal, S. Nekkalapu, and P. Kumar, "2-D Analytical Subdomain Model for Hybrid Dual-Rotor Motor," IEEE Transactions on Magnetics, vol. 52, no. 6, pp. 1-9, June 2016, Art no. 8103609.

[29] O. de la Barrière, S. Hlioui, H. Ben Ahmed, and M. Gabsi, "An Analytical Model for the Computation of No-Load Eddy-Current Losses in the Rotor of a Permanent Magnet Synchronous Machine," IEEE Transactions on Magnetics, vol. 52, no. 6, pp. 1-13, June 2016, Art no. 8103813.

[30] A. Chebak, P. Viarouge, and J. Cros, "Improved Analytical Model for Predicting the Magnetic Field Distribution in High-Speed Slotless Permanent-Magnet Machines," IEEE Transactions on Magnetics, vol. 51, no. 3, pp. 1-4, March 2015, Art no. 8102904.

[31] P. Pfister, X. Yin, and Y. Fang, "Slotted Permanent-Magnet Machines: General Analytical Model of Magnetic Fields, Torque, Eddy Currents, and Permanent-Magnet Power Losses Including the Diffusion Effect," IEEE Transactions on Magnetics, vol. 52, no. 5, pp. 1-13, May 2016, Art no. 8103013.

[32] K. Kazerooni, A. Rahideh, and J. Aghaei, "Experimental Optimal Design of Slotless Brushless PM Machines Based on 2-D Analytical Model," IEEE Transactions on Magnetics, vol. 52, no. 5, pp. 1-16, May 2016, Art no. 8103116.

[33] K. Boughrara, N. Takorabet, R. Ibtiouen, O. Touhami, and F. Dubas, "Analytical Analysis of Cage Rotor Induction Motors in Healthy, Defective, and Broken Bars Conditions," IEEE Transactions on Magnetics, vol. 51, no. 2, pp. 1-17, Feb. 2015, Art no. 8200317.

[34] A. Dalal and P. Kumar, "Analytical Model for Permanent Magnet Motor With Slotting Effect, Armature Reaction, and Ferromagnetic Material Property," IEEE Transactions on Magnetics, vol. 51, no. 12, pp. 1-10, Dec. 2015, Art no. 8114910. 
[35] A. Penzkofer and K. Atallah, "Analytical Modeling and Optimization of Pseudo-Direct Drive Permanent Magnet Machines for Large Wind Turbines," IEEE Transactions on Magnetics, vol. 51, no. 12, pp. 114, Dec. 2015, Art no. 8700814.

[36] T. L. Tiang, D. Ishak, C. P. Lim, and M. K. M. Jamil, "A Comprehensive Analytical Subdomain Model and Its Field Solutions for Surface-Mounted Permanent Magnet Machines," IEEE Transactions on Magnetics, vol. 51, no. 4, pp. 1-14, April 2015, Art no. 8104314.

[37] B. Hannon, P. Sergeant, and L. Dupré, "2-D Analytical Subdomain Model of a Slotted PMSM With Shielding Cylinder," IEEE Transactions on Magnetics, vol. 50, no. 7, pp. 1-10, July 2014, Art no. 8101410.

[38] C. Xia, Z. Zhang, and Q. Geng, "Analytical Modeling and Analysis of Surface Mounted Permanent Magnet Machines With Skewed Slots," IEEE Transactions on Magnetics, vol. 51, no. 5, pp. 1-8, May 2015, Art no. 8104508.

[39] L. J. Wu, Z. Q. Zhu, D. Staton, M. Popescu, and D. Hawkins, "Analytical Model for Predicting Magnet Loss of Surface-Mounted Permanent Magnet Machines Accounting for Slotting Effect and Load," IEEE Transactions on Magnetics, vol. 48, no. 1, pp. 107-117, Jan. 2012.

[40] L. J. Wu, Z. Q. Zhu, D. Staton, M. Popescu, and D. Hawkins, "An Improved Subdomain Model for Predicting Magnetic Field of Surface-Mounted Permanent Magnet Machines Accounting for Tooth-Tips," IEEE Transactions on Magnetics, vol. 47, no. 6, pp. 1693-1704, June 2011.

[41] H. Moayed-Jahromi, A. Rahideh, and M. Mardaneh, "2-D Analytical Model for External Rotor Brushless PM Machines," IEEE Transactions on Energy Conversion, vol. 31, no. 3, pp. 1100-1109, Sept. 2016.
[42] A. Rahideh, A. Ghaffari, A. Barzegar, and A. Mahmoudi, "Analytical Model of Slotless Brushless PM Linear Motors Considering Different Magnetization Patterns," IEEE Transactions on Energy Conversion, vol. 33, no. 4, pp. 1797-1804, Dec. 2018.

[43] T. Lubin, S. Mezani, and A. Rezzoug, "Development of a 2-D Analytical Model for the Electromagnetic Computation of AxialField Magnetic Gears," IEEE Transactions on Magnetics, vol. 49, no. 11, pp. 5507-5521, Nov. 2013.

[44] T. Lubin, S. Mezani, and A. Rezzoug, "Simple Analytical Expressions for the Force and Torque of Axial Magnetic Couplings," IEEE Transactions on Energy Conversion, vol. 27, no. 2, pp. 536546, June

\section{APPENDIX}

Implementing (14) results in

$$
\hat{a}_{n}^{m} n\left(\frac{R_{i m}}{R_{i a}}\right)^{n}-\hat{b}_{n}^{i m} \frac{n}{R_{i m}}+\left.\frac{d\left(k_{n 1}^{i m}\right)}{d r}\right|_{r=R_{i m}}+\mu_{0} M_{h}^{\theta}=0
$$$$
\hat{c}_{n}^{m} n\left(\frac{R_{i m}}{R_{i a}}\right)^{n}-\hat{d}_{n}^{i m} \frac{n}{R_{i m}}+\left.\frac{d\left(K_{n 2}\right)}{d r}\right|_{r=R_{i m}}+\mu_{0} N_{h}^{\theta}=0
$$

Imposing (15) yields the following equations:

\begin{tabular}{|l|}
\hline$\hat{a}_{n}^{m}+\hat{b}_{n}^{m}\left(\frac{R_{i m}}{R_{i a}}\right)^{n}+K_{n 1}\left(R_{i a}\right)=\frac{1}{\pi} \int_{-\pi}^{\pi}\left[a_{0}^{i a}+\sum_{n=1}^{\infty}\left(\hat{a}_{n}^{i a}\left(\frac{R_{i a}}{R_{i r}}\right)^{n}+\hat{b}_{n}^{i a}\right) \cos (n \theta)+\sum_{n=1}^{\infty}\left(\hat{c}_{n}^{i a}\left(\frac{R_{i a}}{R_{i r}}\right)^{n}+\hat{d}_{n}^{i a}\right) \sin (n \theta)\right] \cos (n \theta) d \theta$ \\
\hline$\hat{c}_{n}^{m}+\hat{d}_{n}^{m}\left(\frac{R_{i m}}{R_{i a}}\right)^{n}+K_{n 2}\left(R_{i a}\right)=\frac{1}{\pi} \int_{-\pi}^{\pi}\left[a_{0}^{i a}+\sum_{n=1}^{\infty}\left(\hat{a}_{n}^{i a}\left(\frac{R_{i a}}{R_{i r}}\right)^{n}+\hat{b}_{n}^{i a}\right) \cos (n \theta)+\sum_{n=1}^{\infty}\left(\hat{c}_{n}^{i a}\left(\frac{R_{i a}}{R_{i r}}\right)^{n}+\hat{d}_{n}^{i a}\right) \sin (n \theta)\right] \sin (n \theta) d \theta$ \\
\hline
\end{tabular}

From boundary condition (16) the following equations are obtained

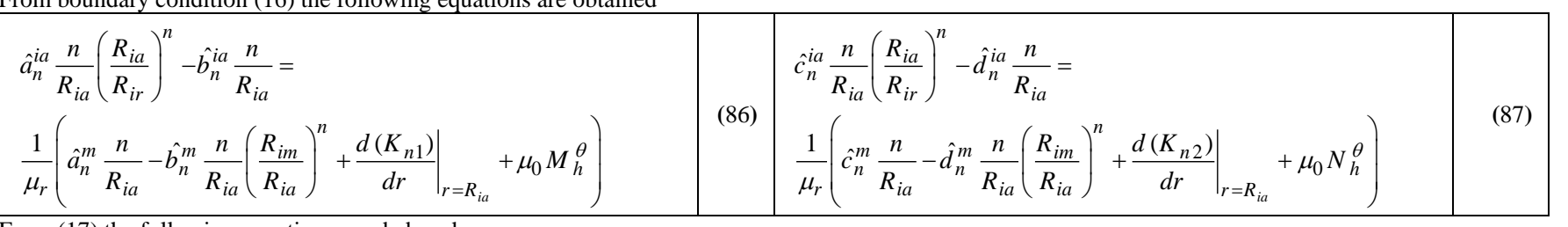

From (17) the following equations are deduced.

\begin{tabular}{|l|l|}
\hline$a_{0}^{i_{r}}+\hat{b}_{0}^{i_{r}} \ln \left(R_{i r}\right)=\frac{1}{\beta} \int_{\theta_{r_{i}}}^{\theta_{r_{i}}} \int_{n=1}^{\beta}\left[a_{0}^{i a}+\sum_{n=1}^{\infty}\left(\hat{a}_{n}^{i a}+\hat{b_{n}^{i a}}\left(\frac{R_{i a}}{R_{i s}}\right)^{n}\right) \cos (n \theta)+\sum_{n}^{\infty}\left(\hat{c}_{n}^{i a}+\hat{d}_{n}^{i a}\left(\frac{R_{i a}}{R_{i s}}\right)^{n}\right) \sin (n \theta)\right] d \theta$ \\
\hline$\hat{a}_{k}^{r_{i}}+\hat{b}_{k}^{r_{i}}\left(\frac{R_{i r}}{R_{\text {oa }}}\right)^{\frac{k \pi}{\beta}}=\frac{2}{\beta} \int_{\theta_{r_{i}}}^{\theta_{r_{i}}+\beta}\left[a_{0}^{i a}+\sum_{n=1}^{N}\left(\hat{a}_{n}^{i a}+\hat{b}_{n}^{i a}\left(\frac{R_{i a}}{R_{i r}}\right)^{n}\right) \cos (n \theta)+\sum_{n=1}^{N}\left(\hat{c}_{n}^{i a}+\hat{d}_{n}^{i a}\left(\frac{R_{i a}}{R_{i r}}\right)^{n}\right) \sin (n \theta)\right] \cos \left(\frac{k \pi}{\beta}\left(\theta-\theta_{r_{i}}\right)\right) d \theta$
\end{tabular}

Implementing (18) the following equations:

\begin{tabular}{|l|l|l|}
$\hat{a}_{n}^{i a} \frac{n}{R_{i r}}-\hat{b}_{n}^{i a} \frac{n}{R_{i r}}\left(\frac{R_{i a}}{R_{i r}}\right)^{n}=\frac{1}{\pi} \int_{\theta_{r_{i}}}^{\theta_{r_{i}}+\beta}\left[\sum_{i=1}^{N_{r}} \frac{b_{0}^{r_{i}}}{R_{i r}}+\sum_{i=1}^{N_{r}} \sum_{k=1}^{K}\left(\hat{a}_{k}^{r_{i}} \frac{-k \pi}{R_{i r} \beta}+\hat{b}_{k}^{r_{i}} \frac{k \pi}{R_{i r} \beta}\left(\frac{R_{o a}}{R_{i r}}\right)^{\frac{k \pi}{\beta}}\right) \cos \left(\frac{k \pi}{\beta}\left(\theta-\theta_{r_{i}}\right)\right)\right] \cos (n \theta) d \theta$ \\
\hline$\hat{c}_{n}^{i a} \frac{n}{R_{i r}}-\hat{d}_{n}^{i a} \frac{n}{R_{i r}}\left(\frac{R_{i a}}{R_{i r}}\right)^{n}=\frac{1}{\pi} \int_{\theta_{r_{i}}}^{\theta_{r_{i}}+\beta}\left[\sum_{i=1}^{N_{r}} \frac{b_{0}^{r_{i}}}{R_{i r}}+\sum_{i=1}^{N_{r}} \sum_{k=1}^{K}\left(\hat{a}_{k}^{r_{i}} \frac{-k \pi}{R_{i r} \beta}+\hat{b}_{k}^{r_{i}} \frac{k \pi}{R_{i r} \beta}\left(\frac{R_{o a}}{R_{i r}}\right)^{\frac{k \pi}{\beta}}\right) \cos \left(\frac{k \pi}{\beta}\left(\theta-\theta_{r_{i}}\right)\right)\right] \sin (n \theta) d \theta$ \\
\hline
\end{tabular}


Imposing boundary condition (19) yields the following expressions:

$$
\begin{aligned}
& a_{0}^{r_{i}}+b_{0}^{r_{i}} \ln \left(R_{o a}\right)=\frac{1}{\beta} \int_{\theta_{r_{i}}}^{\theta_{r_{i}}^{+\beta}}\left[\sum_{n=1}^{N}\left(\hat{a}_{n}^{o a}\left(\frac{R_{o a}}{R_{\text {so }}}\right)^{n}+\hat{b}_{n}^{o a}\right) \cos (n \theta)+\sum_{n=1}^{N}\left(\hat{c}_{n}^{o a}\left(\frac{R_{o a}}{R_{s o}}\right)^{n}+\hat{d}_{n}^{o a}\right) \sin (n \theta)\right] d \theta \\
& \hat{a}_{k}^{r_{i}}\left(\frac{R_{i r}}{R_{\text {oa }}}\right)^{\frac{k \pi}{\beta}}+\hat{b}_{k}^{r_{i}}=\frac{2}{\beta} \int_{\theta_{r_{i}}}^{\theta_{r_{i}}^{+\beta}}\left[\sum_{n=1}^{N}\left(\hat{a}_{n}^{o a}\left(\frac{R_{o a}}{R_{\text {so }}}\right)^{n}+\hat{b}_{n}^{o a}\right) \cos (n \theta)+\sum_{n=1}^{N}\left(\hat{c}_{n}^{o a}\left(\frac{R_{o a}}{R_{\text {so }}}\right)^{n}+\hat{d}_{n}^{o a}\right) \sin (n \theta)\right] \cos \left(\frac{k \pi}{\beta}\left(\theta-\theta_{r_{i}}\right)\right) d \theta
\end{aligned}
$$

Imposing boundary condition (20) yields the following equations:

$$
\begin{array}{|l}
\hat{a}_{n}^{o a} \frac{n}{R_{o a}}\left(\frac{R_{o a}}{R_{\text {so }}}\right)^{n}-\hat{b}_{n}^{o a} \frac{n}{R_{o a}}=\frac{1}{\pi} \int_{\theta_{r_{i}}}^{\theta_{r_{i}}+\beta}\left[\sum_{i=1}^{N_{r}} \frac{b_{0}^{r_{i}}}{R_{o a}}+\sum_{i=1}^{N_{r}} \sum_{k=1}^{K}\left(\hat{a}_{k}^{r_{i}} \frac{-k \pi}{\beta R_{o a}}\left(\frac{R_{i s}}{R_{o a}}\right)^{\frac{k \pi}{\beta}}+\hat{b}_{k}^{r_{i}} \frac{-k \pi}{\beta R_{o a}}\right) \cos \left(\frac{k \pi}{\beta}\left(\theta-\theta_{r_{i}}\right)\right) \cos (n \theta) d \theta\right. \\
\hat{c}_{n}^{o a} \frac{n}{R_{o a}}\left(\frac{R_{o a}}{R_{s o}}\right)^{n}-\hat{d}_{n}^{o a} \frac{n}{R_{o a}}=\frac{1}{\pi} \int_{\theta_{r_{i}}}^{\theta_{r_{i}}+\beta}\left[\sum_{i=1}^{N_{r}} \frac{b_{0}^{r_{i}}}{R_{o a}}+\sum_{i=1}^{N_{r}} \sum_{k=1}^{K}\left(\hat{a}_{k}^{r_{i}} \frac{-k \pi}{\beta R_{o a}}\left(\frac{R_{i r}}{R_{o a}}\right)^{\frac{k \pi}{\beta}}+\hat{b}_{k}^{r_{i}} \frac{k \pi}{\beta R_{o a}}\right) \cos \left(\frac{k \pi}{\beta}\left(\theta-\theta_{r_{i}}\right)\right) \sin (n \theta) d \theta\right.
\end{array}
$$

$$
\begin{aligned}
& A_{0}^{s o_{j}}+B_{0}^{s o_{j}} \ln \left(R_{s o}\right)=\frac{1}{\sigma} \int_{\theta_{s o}}^{\theta_{s o_{j}}+\sigma}\left[\left(\hat{a}_{n}^{o a}+\hat{b}_{n}^{o a}\left(\frac{R_{s o}}{R_{o a}}\right)^{-n}\right) \cos (n \theta)+\left(\hat{c}_{n}^{o a}+\hat{d}_{n}^{o a}\left(\frac{R_{s o}}{R_{o a}}\right)^{-n}\right) \sin (n \theta)\right] d \theta \\
& \hat{a}_{u}^{s o_{j}}+\hat{b}_{u}^{s o_{j}}\left(\frac{R_{s o}}{R_{i s}}\right)^{\frac{u \pi}{\sigma}}=\frac{2}{\sigma} \int_{\theta_{s o_{j}}}^{\theta_{s o_{j}}+\sigma}\left[\sum_{n=1}^{N}\left(\hat{a}_{n}^{o a}+\hat{b}_{n}^{o a}\left(\frac{R_{o a}}{R_{s o}}\right)^{n}\right) \cos (n \theta)+\sum_{n=1}^{N}\left(\hat{c}_{n}^{o a}+\hat{d}_{n}^{o a}\left(\frac{R_{o a}}{R_{s o}}\right)^{n}\right) \sin (n \theta)\right] \cos \left(\frac{u \pi}{\sigma}\left(\theta-\theta_{s o_{j}}\right)\right) d \theta
\end{aligned}
$$

Imposing boundary condition (22), the following equations are obtained:

$$
\begin{aligned}
& \hat{a}_{n}^{o a} \frac{n}{R_{s o}}-\hat{b}_{n}^{o a} \frac{n}{R_{s o}}\left(\frac{R_{s o}}{R_{o a}}\right)^{-n}=\frac{1}{\pi} \int_{\theta_{s o_{j}}}^{\theta_{s o_{j}}+\sigma}\left[\sum_{j=1}^{N_{s}} \frac{b_{0}^{s o_{j}}}{R_{s o}}+\sum_{j=1}^{N_{s}} \sum_{u=1}^{\infty}\left(\hat{a}_{u}^{s o_{j}} \frac{-u \pi}{\sigma R_{s o}}+\hat{b}_{u}^{s o_{j}} \frac{u \pi}{\sigma R_{s o}}\left(\frac{R_{s o}}{R_{i s}}\right)^{\frac{u \pi}{\sigma}}\right) \cos \left(\frac{u \pi}{\sigma}\left(\theta-\theta_{s o_{j}}\right)\right)\right] \cos (n \theta) d \theta \\
& \hat{c}_{n}^{o a} \frac{n}{R_{s o}}-\hat{d}_{n}^{o a} \frac{n}{R_{s o}}\left(\frac{R_{s o}}{R_{o a}}\right)^{-n}=\frac{1}{\pi} \int_{\theta_{s o_{j}}}^{\theta_{s o_{j}}+\sigma}\left[\sum_{j=1}^{N_{s}} \frac{b_{0}^{s o_{j}}}{R_{s o}}+\sum_{j=1}^{N_{s}} \sum_{u=1}^{U}\left(\hat{a}_{u}^{s o_{j}} \frac{-u \pi}{\sigma R_{s o}}+\hat{b}_{u}^{s o_{j}} \frac{u \pi}{\sigma R_{s o}}\left(\frac{R_{s o}}{R_{i s}}\right)^{\frac{u \pi}{\sigma}}\right] \cos \left(\frac{u \pi}{\sigma}\left(\theta-\theta_{s o_{j}}\right)\right)\right] \sin (n \theta) d \theta
\end{aligned}
$$

Imposing boundary condition (23) results in:

$$
\begin{aligned}
& A_{0}^{s o_{j}}+B_{0}^{s o_{j}} \ln \left(R_{i s}\right)=\frac{1}{\sigma} \int_{\theta_{s o_{j}}}^{\theta_{s o_{j}}+\sigma}\left[a_{0}^{s_{j}}+b_{0}^{s_{j}} \ln \left(R_{i s}\right)+K_{0}\left(R_{i s}\right)+\sum_{v=1}^{\infty}\left(\hat{a}_{v}^{s_{j}}+\hat{b}_{v}^{s_{j}}\left(\frac{R_{i s}}{R_{o s}}\right)^{\frac{v \pi}{\psi}}+K_{v}\left(R_{i s}\right)\right) \cos \left(\frac{v \pi}{\psi}\left(\theta-\theta_{s_{j}}\right)\right) d \theta\right. \\
& \hat{a}_{u}^{s o_{j}}\left(\frac{R_{i s}}{R_{s o}}\right)^{-\frac{u \pi}{\sigma}}+\hat{b}_{u}^{s o_{j}}=\frac{1}{\sigma} \int_{\theta_{s o_{j}}}^{\theta_{s o_{j}} \sigma}\left[a_{0}^{s_{j}}+b_{0}^{s_{j}} \ln \left(R_{i s}\right)+K_{0}\left(R_{i s}\right)+\sum_{v=1}^{\infty}\left(\hat{a}_{v}^{s_{j}}+\hat{b}_{v}^{s_{j}}\left(\frac{R_{i s}}{R_{o s}}\right)^{\frac{v \pi}{\psi}}+K_{v}\left(R_{i s}\right)\right) \cos \left(\frac{v \pi}{\psi}\left(\theta-\theta_{s_{j}}\right)\right)\right] \cos \left(\frac{u \pi}{\sigma}\left(\theta-\theta_{s o_{j}}\right)\right) d \theta
\end{aligned}
$$

Imposing boundary conditions (24) results in:

$$
\begin{aligned}
& \frac{b_{0}^{s_{j}}}{\mu_{r}^{s_{j}} R_{i s}}+\frac{K_{0}\left(R_{i s}\right)}{2 R_{i s}}=\frac{1}{\psi} \int_{\theta_{s o_{j}}}^{\theta_{s o_{j}}+\sigma}\left[\frac{b_{0}^{s o_{j}}}{R_{i s}}+\sum_{u=1}^{\infty}\left(\hat{a}_{u}^{s o_{j}} \frac{-u \pi}{\sigma R_{i s}}\left(\frac{R_{i s}}{R_{o a}}\right)^{\frac{-u \pi}{\sigma}}+\hat{b}_{u}^{s o_{j}} \frac{u \pi}{\sigma R_{i s}}\right) \cos \left(\frac{u \pi}{\sigma}\left(\theta-\theta_{s o_{j}}\right)\right) d \theta\right. \\
& \hat{a}_{v}^{s_{j}} \frac{-v \pi}{\mu_{r}^{s_{j}} \psi R_{i s}}+\hat{b}_{v}^{s_{j}} \frac{v \pi}{\mu_{r}^{s_{j}} \psi R_{i s}}\left(\frac{R_{i s}}{R_{o s}}\right)^{\frac{v \pi}{\psi}}+\frac{2}{\mu_{r}^{s_{j}}} K_{v}\left(R_{i s}\right)=\frac{2}{\psi} \int_{\theta_{s o_{j}}}^{\theta_{s o_{j}}+\sigma}\left[\frac{b_{0}^{s o_{j}}}{R_{i s}}+\sum_{u=1}^{\infty}\left(\hat{a}_{u}^{s o_{j}} \frac{-u \pi}{\sigma R_{i s}}\left(\frac{R_{i s}}{R_{o a}}\right)^{\frac{-u \pi}{\sigma}}+\hat{b}_{u}^{s o_{j}} \frac{u \pi}{\sigma R_{i s}}\right) \cos \left(\frac{u \pi}{\sigma}\left(\theta-\theta_{s o_{j}}\right)\right)\right] \cos \left(\frac{v \pi}{\psi}\left(\theta-\theta_{s_{j}}\right)\right) d \theta
\end{aligned}
$$

Imposing boundary condition (25) results in:

$$
\begin{array}{|l|l|l}
b_{0}^{s_{j}}=-\frac{1}{2} K_{0}\left(R_{o s}\right) & \text { (104) } & \hat{a}_{v}^{s_{j}} \frac{-v \pi}{\psi R_{o s}}\left(\frac{R_{o s}}{R_{i s}}\right)^{\frac{-v \pi}{\psi}}+\hat{b}_{v}^{s_{j}} \frac{v \pi}{\psi R_{o s}}+\frac{2}{R_{o s}} K_{v}\left(R_{o s}\right)=0
\end{array}
$$

$$
\text { And from (55): }
$$

$$
\sum_{i=1}^{N_{r}} b_{0}^{r_{i}}=0
$$

By rewriting (82) - (106) in a matrix and vector form, a set of linear simultaneous algebraic equations with the same number of unknown variables, must be solved. 